\title{
Heterogeneous Passthrough from TFP to Wages*
}

Preliminary and Incomplete. Please do not cite.

\author{
Mons Chan ${ }^{\dagger} \quad$ Sergio Salgado ${ }^{\ddagger} \quad$ Ming $\mathrm{Xu}^{\S}$
}

February 2019

\begin{abstract}
In this paper, we use matched employer-employee data from Denmark to analyze the extent to which firms' productivity shocks are passed to workers wages. The richness of our dataset allows us to separately study continuing and non-continuing workers (switchers), to correct for selection, and to investigate how the passthrough varies across narrow population groups. Our results show a much larger degree of passthrough from firms' shocks to workers' wages than reported in previous research. On average, an increase of one standard deviation in firm-level TFP commands an increase of $3.0 \%$ in annual wages ( $\$ 1500$ USD for the average worker). Furthermore, we find that the effect of productivity shocks on wage growth for switchers is of larger magnitude relative to workers that stay in the same firm. Finally, we find large differences in the passthrough of productivity shocks to wages for workers of different income levels, ages, industries, and working in firms of different productivity levels. In the second part of our paper, we estimate a stochastic process of income that captures the salient features of the relation between firm-level shocks and the passthrough to workers' wages. We then embed the estimated stochastic process into a life-cycle consumption savings model with incomplete markets in order to evaluate the welfare and distributional implications of the passthrough from firm's TFP shocks to worker's wages we observe in the data.
\end{abstract}

*We thank Fatih Guvenen, Sergio Ocampo, the participants at the 2nd Dale T. Mortensen Centre Conference, the SEA 2018 meetings, and the Macro-Labor Workshop at the University of Minnesota for helpful comments and discussions. First version: October 2018.

$\dagger$ Aarhus University. E-mail: mons@econ.au.dk

$\ddagger$ University of Minnesota. E-mail: salga010@umn.edu

$\S$ Aarhus University. E-mail: ming@econ.au.dk 


\section{Introduction}

What is the role of firm productivity shocks in workers' income instability? How much of the dispersion in wage growth is explained by shocks affecting firms? How does the passthrough from firm shocks to wages vary across firms and workers of different characteristics and over time? In this paper, we answer these questions and reevaluate the importance of shocks to firms for labor income growth, income instability, and welfare. In particular, we use matched employer-employee data from Denmark to study the extent to which productivity shocks are passed to worker wage growth.

To get a better sense of the large heterogeneity present in firm productivity and labor earnings growth figure 1 shows the density of workers' wage changes and firms' Total Factor Productivity (TFP) changes. Both distributions show significant dispersion and wide tails indicating large swings in wages and productivity. Importantly, the changes in firms' TFP and the changes in workers' wages are correlated. Figure 2 displays the unconditional mean and standard deviation of wage growth within percentiles of the TFP growth distribution for continuing workers. ${ }^{1}$ The left panel shows that workers at high growth firms (those in the top decile of the TFP growth distribution) experience wage growth that is three times higher on average than the wage growth experienced by workers at low growth firms (those at the bottom decile of the TFP growth distribution, typically declining productivity firms). Furthermore, the right panel of figure 2 shows that individuals who work at high or low TFP growth firms experience almost twice as much wage growth dispersion in a given year relative to individuals working in firms in the middle of the TFP growth distribution.

We provide four major empirical results. First, we use individual-level panel data on every person in Denmark to study the effects of firm-level shocks separately for stayers (workers that remain in the firm), switchers (workers that change firms), and those transitioning in and out of unemployment. This enables us to estimate the effect of productivity shocks on wages separately from the effects of job separation. Second, the existing literature has focused almost exclusively in continuing workers ignoring the endogenous selection for firms and workers into the sample. Endogenous selection on the workers' side can arise, for instance, when workers who would have gotten a large passthrough when their firm experiences a large TFP shock switch firms to avoid a decline in their wages. Similarly, a firm that normally passes its shocks to wages may go out of business after a large productivity drop.

\footnotetext{
${ }^{1}$ Details on the sample selection as well as the calculation of labor income and firm-level productivity are discussed in section 3 and section 4 .
} 
Figure 1: Distribution of Changes in TFP and Wages

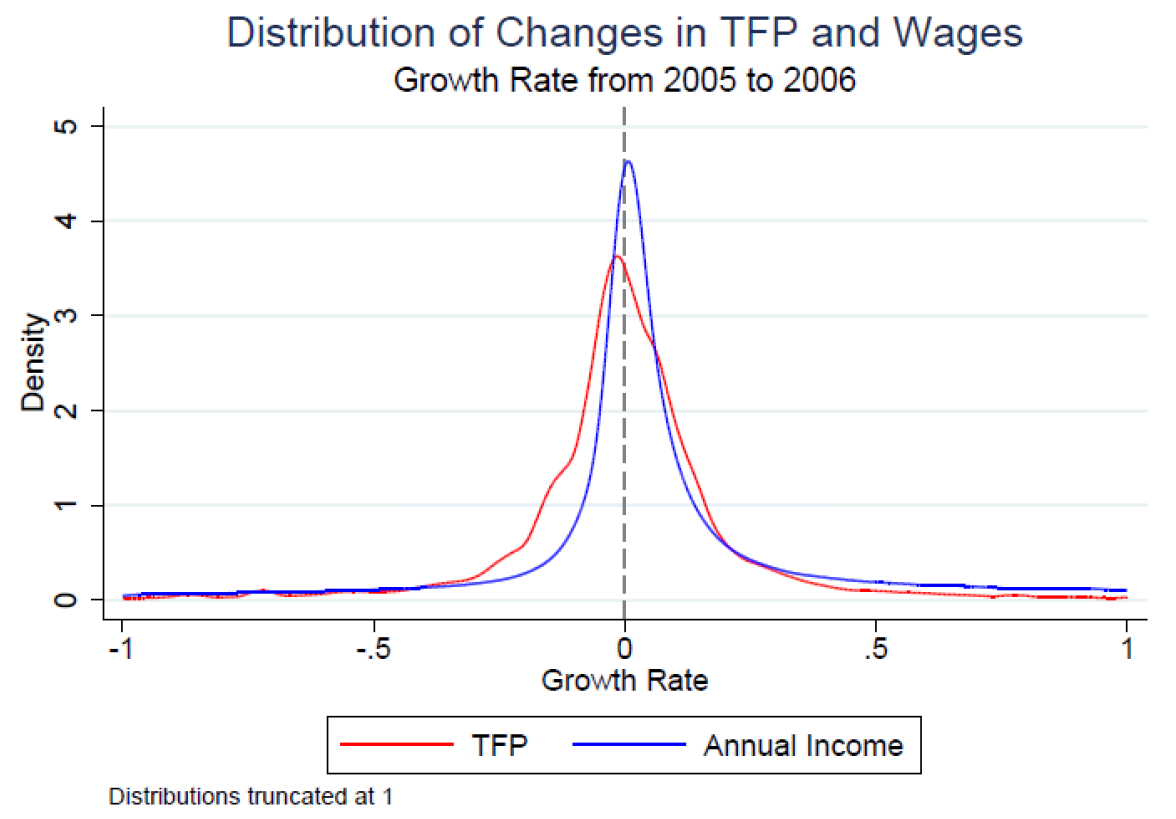

Note: The red line in figure 1 shows the distribution of one-year log change in firm-level Total Factor Productivity (TFP) calculated for a sample of Danish firms that have more than one employee in 2005 and 2006. The blue line shows the distribution of the log change of real annual earnings for a sample of Danish workers between 2005 and 2006. See section 2 for additional details in the sample selection.

Ignoring this selection problem could underestimate the passthrough effect and overstate firms' insurance against shocks. In this paper, we address these concerns by using exogenous variation derived from spousal linkages. Third, we use the richness of our dataset to provide a direct measure of firm-level TFP for the entire private sector of the Danish economy. Our methodology allows us to separately study the effects of persistent vs. transitory shocks to firm TFP as well as asymmetric passthrough from TFP to wages. This is a significant departure from the existing literature which, mostly due to data limitations, uses indirect measures of productivity such as value-added, revenues, or output per worker ${ }^{2}$. Fourth, we exploit the breadth of our dataset to study how the passthrough from firm shocks to worker wages varies within narrow population groups defined simultaneously by firm characteristics (industry, size, productivity level, etc.) and worker characteristics (age, education, income level, tenure, etc.), and over the business cycle.

Our novel approach for controlling for selection bias exploits linked spousal information.

\footnotetext{
${ }^{2}$ For instance, Juhn et al. (2018) use the change in revenues as the firm-level shock affecting workers' earnings and Guiso et al. (2005) use the residuals of a regression of value added on firm-level observables.
} 
Figure 2: Wage Growth Across the TFP Growth Distribution
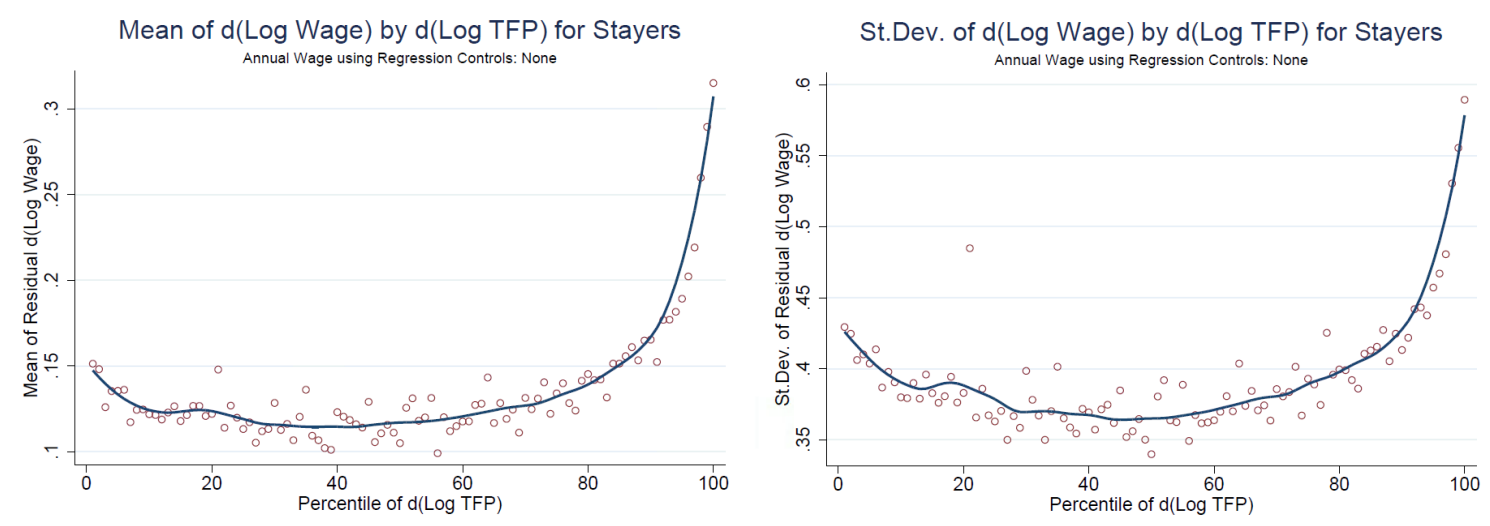

Note: The left (right) panel of figure 2 shows the average of (standard deviation of ) the wage growth within each percentile of the firm-level TFP growth distribution for a sample of Danish workers and firms. See section 2 for additional details in the sample selection.

In particular, we use variation in marriage status, spousal employment decisions and income shocks to estimate the probability that individual moves across firms. Our identification strategy rests on the assumption that changes in a spouse's income, employment status, or spouse's firm productivity, has a significant impact on the decision of an individual to stay or not in a particular job, but such changes are uncorrelated with the worker's within-firm wage growth or the productivity shocks affecting the firm where the individual works (unless both spouses work at the same firm, which we excluded in our data). We find that controlling for selection greatly increases the estimated passthrough from firms' productivity shocks to workers' wages.

Overall we find large and economically significant passthrough from firm shocks to wages. In particular, after we have controlled for selection, we find that an individual who works at a firm which experiences an increase of TFP of one standard deviation receives an increase in annual earnings of $\$ 1,500$, which is around $3 \%$ of the Danish income per capita. Considering that in any given year 33\% of firms and $40 \%$ of workers in Denmark experience a persistent or transitory TFP shock of at least one standard deviation away from the average, the effect of firm-level shocks on wages is quite substantial not only at the micro- but also at the macro-level.

The effect of TFP changes on workers that transition across firms has been largely ignored by the literature and to the best of our knowledge, ours is the first paper analyzing separately the impact of productivity shocks on the wage of workers that switch across firms. Analyzing 
this group is important as they represent a large fraction of the workforce: in any given year around $20 \%$ of full-time danish workers change employer. We find that the effect of betweenfirm productivity differences on the wages of individuals that move across firms is large and of greater magnitude than the effect of within-firm TFP shocks on the wages of stayers. In particular, a worker that moves across firms whose TFP differ by one standard deviation experiences an income change of $\$ 5,200^{3}$.

We also contribute to the existing literature by investigating how passthrough differs across firm and worker types and over the business cycle. First, we analyze the differential effect of productivity shocks for workers at high and low ranks of the income distribution. We find that high wage workers (those in the 5th quintile of the income distribution) are much less insulated from changes in firm productivity than low wage workers (those in the 1st quintile of the income distribution). In fact, we find that the passthrough for high wage workers is three to four times larger than the passthrough for low wage workers. Young workers (workers of 35 years or less) are also more exposed to firms productivity shocks than older workers (workers of 50 years or more). This is because young workers work in firms that in general pass a larger proportion of shocks to wages and because the volatility of productivity shocks of the firms where young people work is higher. We also find substantial heterogeneity in passthrough for firms in different industries. For workers in the Transportation or Hospitality sectors the passthrough is two to three times larger than passthrough for workers in ICT or Finance. This is surprising considering that Finance has a larger fraction of workers under performance pay schemes that typically tie workers' income to firms' outcomes.

Motivated by the robust empirical evidence that firm productivity shocks have a significant impact on workers wages, in the second part of our paper we estimate a flexible stochastic process of income that captures the salient features of the relation between firmlevel shocks and the passthrough to workers' wages. In particular, we consider an income process similar to Low et al. (2010) modified to take into account the rich heterogeneity in passthrough observed in the data. To capture the marked asymmetry of passthrough between positive and negative shocks, our preferred specification considers a passthrough coefficient of firm's productivity to wages that is different depending on the sign of the productivity change. Our estimation, which is carried out using indirect inference, suggests a large role for firms in determining income growth dispersion and income inequality.

In the final part of our paper, we embed the estimated stochastic process into a life-cycle

\footnotetext{
${ }^{3}$ Note that the TFP change for switchers is the difference in productivity between two different firms rather than the within-firm shock to productivity.
} 
consumption savings model with incomplete markets. This framework allows us to calculate the welfare and distributional implications of the partial and heterogeneous passthrough we document in this paper. Our model does a good job in accounting for the extent of income and wealth inequality we observe in Denmark. In our main quantitative exercise, we ask how much value the workers in this economy, in terms of lifetime consumption, assign to the insurance provided by firms. We do so by comparing our benchmark economy to an economy in which firms' shocks are fully passed to workers wages (passthrough equal to one). Our preliminary results suggest that the insurance provided by firms is of little value for workers. This is because an increase in the passthrough has two opposite effects on welfare. On the one hand, higher passthrough has a negative impact as it increases earnings instability. On the other hand, because a larger fraction of the positive shocks is passed to workers their average wage increases. The overall effect depends on the ability of workers to insure against the increase in income risk. In our current steady-state comparison with infinitely lived workers with access to a risk-free asset, an individual has enough time to offset the negative impact of an increase in wage dispersion by increasing savings. In other words, a risk free asset provides enough flexibility to workers to compensate for the decline in the insurance provided by firms by increasing capital accumulation. At the same time, higher average permanent income reduces the necessity of workers to save. These two offsetting

effects imply a muted impact on welfare from an increase in the passthrough of firms' shocks to workers' wages and a small increase in capital in the economy. Our ongoing work aims to fully account for the life cycle income profile and have a more realistic asset market that resembles the frictions in the financial market faced by workers, both of which will likely increase the value of the insurance provided by firms.

\section{Literature Review}

Our paper relates to several strands of the literature. First and foremost, we contribute to the literature that studies the relationship between firm shocks and worker earnings. Guiso et al. (2005) analyze the degree of insurance provided by firms using matched employeeemployer data from Italy. Their paper, however, does not analyze how firm-level productivity affects employment transitions which might explain a large fraction of the earnings instability observed in the data. Barth et al. (2016) and Juhn et al. (2018) also study the heterogeneity of passthrough from firm's shocks to wages. Barth et al. (2016) report that almost three quarters of the dispersion in wage levels is accounted for by differences in TFP levels across firms whereas worker characteristics contribute little. Bagger et al. (2014) use Danish data 
to study the importance of firm level productivity for wage level dispersion, the role of rent sharing between workers and firms, and labor force composition within the firm. They document an important role for fixed TFP differences across firms in the determination of earnings level dispersion. These papers, however, do not analyze the role of firm-level TFP shocks for the dispersion of earnings growth and do not take into account the effects of firm level shocks on employment transitions. ${ }^{4}$ Similarly, none of these papers address the selection issue which is at the center of our paper.

Our paper also contributes to the understanding of labor income risk. Since the seminal work of Gottschalk et al. (1994), several papers have studied the extent of labor income instability and its evolution over time ${ }^{5}$. Due to data limitations, however, most of the papers in the literature do not consider the role of firms in driving labor income instability. An exception is the work of Comin et al. (2009) that studies whether firm's revenue volatility is passed to average wage instability using data from a panel of publicly traded firms and worker level information from survey-level data. The authors find a positive relation between firms and worker wage volatility. Relative to this paper, we use an employer-employee matched administrative data set that allows us to have a tighter link between firm shocks and earnings instability.

The rest of the paper unfolds as follows: In section 2, we introduce our data source and sample selection. We then discuss our estimation strategy for our various specifications of analysis in section 3. The baseline model and results with and without selection correction are shown in section 4 . We then proceed to explore various dimensions of heterogeneity along workers, firms and the timing dimension in section 5. Section 6 looks at the long term effects of TFP shocks on wages as well as further robustness checks. Section 7 presents our quantitative analysis. Section 8 concludes our work.

\section{Data}

Our main source of information is a matched employer-employee administrative dataset from Statistics Denmark. We combine several large panel datasets for our analysis. Worker data

\footnotetext{
${ }^{4}$ Other recent related ongoing projects using US data (Lamadon et al. (2017)) and Swedish data (Friedrich et al. (2014)) also use value added and output per worker as measures of firm level productivity shocks instead of TFP.

${ }^{5}$ See for instance Sabelhaus and Song (2009), Sabelhaus and Song (2010), Ziliak et al. (2011), and Guvenen et al. (2014).
} 
Table 1: Summary Statistics

\begin{tabular}{|c|c|c|c|}
\hline \multirow[b]{3}{*}{ Annual Wages (dkk) } & Mean & Std.der & $\mathrm{N}$ \\
\hline & \multicolumn{3}{|c|}{ Workers Characteristics } \\
\hline & 363,661 & 208,240 & $8.98 \mathrm{M}$ \\
\hline Hourly Wages (dkk) & 234 & 147 & $7.36 \mathrm{M}$ \\
\hline \multirow[t]{2}{*}{ Age } & 41.7 & 11.3 & $8.98 \mathrm{M}$ \\
\hline & \multicolumn{3}{|c|}{ Firms Characteristics } \\
\hline Log Value Added & 14.6 & 1.33 & $0.71 \mathrm{M}$ \\
\hline Log TFP & 7.94 & 0.58 & $0.71 \mathrm{M}$ \\
\hline Firm Age (years) & 13.1 & 12.5 & $0.71 \mathrm{M}$ \\
\hline Number of Employees & 19.8 & 192.7 & $0.71 \mathrm{M}$ \\
\hline
\end{tabular}

Note: Table 1 shows summary statistics for the sample used in our analysis. Monetary values are expressed in Danish kroner.

comes from the Integrated Database for Labor Market Research which contains employment and personal information for the entire population of Denmark. In particular, we observe annual and hourly wages, occupation, labor market status, position within the firm, age, gender, education, and tenure. We also have spousal links, which means we observe the same information for everyone's spouse across time. This spousal information will be crucial when estimating the first-stage selection model we use in 3.4 to correct for selection bias in the passthrough estimation. We match this individual-level panel to a firm-level panel, the Firm Statistics Register, which contains accounting and input use data for the universe of Danish firms. The key variables we use are firm annual revenues, value added, capital stock, intermediate expenditure and employment, as well as firm age, location, and industry. This data allows us to construct robust measures of TFP following the methods developed by Levinsohn and Petrin (2003), Ackerberg et al. (2015), Gandhi et al. (2018), and others. We also link in firm-product data on physical sales, market shares, input and output prices, and imports/exports. This latter data allows us to construct exogenous firm-level TFP shifters so that we can explore the causal relationship between TFP shocks and wage growth.

We restrict our analysis to the period from 2002 to $2012 .{ }^{6}$ For our baseline analysis, we keep all firms in the private sector with at least one employee. We use only full time workers

\footnotetext{
${ }^{6}$ This is primarily due to significant changes in firm and worker classifications which happened around 2002, along with several gaps in the firm level data. We are in the process of extending the years of analysis back to the early 1990s which will allow us to separately identify permanent and transitory shocks to firm profits and worker wages.
} 
who are 15 years and older, whose annual earnings is above 30,000 DKK (about $\$ 4600$ USD), and who are not working in the public sector or are self-employed.

Our sample selection leaves us with about 8.98 million worker-year observations for our primary empirical analysis and 0.71 million firm-year observations. Basic summary statistics can be found in Table $1 .^{7}$

\section{Estimation Strategy}

In this section we discuss our estimation strategy. Section 3.1 describes our baseline regression model. Section 3.3 provides the details of our TFP estimation. Section 3.4 discusses our strategy for dealing with the potential bias of the basic model in section 3.1 due to the selection of workers.

\subsection{Baseline Empirical Specification}

Our basic empirical especification relates changes in worker (log) wages and changes in (log) firm TFP controlling for workes and firms characteristics. The primary model we use is then

$$
\Delta w_{i j t}=\alpha+\beta \Delta \log T F P_{i j t}+\mathbb{Z}_{j t}^{\prime} \gamma+X_{i t}^{\prime} \lambda+\delta_{t}+\varepsilon_{i j t}
$$

where $\Delta w_{i j t}$ is the change of $\log$ real wages for individual $i$ that works in firm $j$ between periods $t$ and $t-1, \Delta \log T F P_{i j t}$ is the change in TFP for firm $j$ over the same period, $\mathbb{Z}_{j t}^{\prime}$ is a set of observable firm-level characteristics that might vary over time (industry, lagged firm size, lagged firm age, lagged firm productivity.), $X_{i t}^{\prime}$ is a set of individual characteristics (age, education, lagged occupation, lagged experience, lagged tenure, job switch indicator, lagged wage.), and $\delta_{t}$ is a year-fixed effect that controls for aggregate economic conditions. The main parameter of interest is $\beta$ which captures the elasticity of wages to changes in firm-level productivity. ${ }^{8}$

\footnotetext{
${ }^{7}$ The remainder of our analysis will be done in USD. The exchange rate at time of writing was roughly 6.55 dkk per USD.

${ }^{8}$ Because our main specification used first-differences in wages and productivity we are implicitly controlling for workers and firms fixed characteristics.
} 


\subsection{Labor Quality and Wages}

In order to identify firm-level productivity in the next section, we want to be able to control for changes in firm-level labor inputs. Our main concern is that if we estimate firm productivity using standard measures of labor inputs (such as a simple count of workers, or number of hours worked), our measure of tfp may include unmeasured differences in the quality of these labor inputs, driving variation in tfp which may be correlated with wages through this channel rather than the passthrough channel we want to measure. To attempt to control for this and peel changes in worker quality out of our measure of firm productivity, we use our worker-side data to construct a quality-adjusted labor input index (the "predicted" wagebill) to use in our production function estimation ${ }^{9}$.

Our method is very simple. Our firm-side data has information on full-time equivalents working in the firm that year, which we denote $E_{j t}$. The standard procedure would be to use this directly in the production function estimation, setting $L_{j t}=E_{j t}$. Instead, we use our worker side data to construct a firm-level average quality-adjusted labor input index, $\widetilde{G}_{j t}$ which we then multiply by the number of full time equivalents to get our firm-level labor input $L_{j t} \equiv \widetilde{G}_{j t} E_{j t}$. To calculate $\widetilde{G}_{j t}$, we estimate a simple mincer regression of log hourly wages $w_{i j t}$ on individual characteristics $X_{i j t}^{m}$ and individual fixed effects $a_{i}^{m}$ :

$$
w_{i j t}=X_{i j t}^{m^{\prime}} \beta^{m}+a_{i}^{m}+\epsilon_{i t}^{m}
$$

We then define a firm's total labor input as $T L_{j t} \equiv \sum_{i} \widehat{W}_{i j t} H_{i j t}$ where $\widehat{W}_{i j t}$ are the predicted hourly wages (in levels) from the mincer regression and $H_{j t}$ are hours worked for worker $i$ employed by firm $j$ in year $t$. Using $H_{i j t}$ and information on the average number of hours $\bar{H}$ worked by full time workers in Denmark, we can also construct a worker-data side measure of a firm's full time equivalents, $\widetilde{E}_{j t}=\sum_{i} H_{i j t} / \bar{H}$. We do this since we observe hourly wages for most but not all workers in every firm. Note that this implicitly assumes that any workers who are not included in the worker data-side calculation of total quality adjusted labor or FTEs are of the same average quality as the observed workers. The firm's quality-adjusted

\footnotetext{
${ }^{9}$ A number of recent papers including Fox and Smeets (2011) argue that controlling for variation in input quality is important for identifying TFP. Fox and Smeets (2011) suggest that using the wage bill as a proxy for worker quality is a possible substitute for directly controlling for worker quality, especially if individuallevel data is not available. However, using the wage bill as the labor input implicitly assumes that wages perfectly represent worker ability, and preclude the ability of firms to adjust wages in response to ex-post or transitory changes in tfp, which is contrary to our findings. To get around this, we use the "predicted" wagebill based on the fixed effects and observable characteristics of the workers at the firm, which accounts for variation across firms in the wages paid to observably identical workers which may stem from differences in wage contracts, tfp passthrough, imperfect labor markets, etc.
} 
average labor input is then $\widetilde{G}_{j t}=T L_{j t} / \widetilde{E}_{j t}$. Our measure of labor input $L_{j t}$ then controls for both firm and individual-level changes in ability as measured through the mincer regression.

\subsection{TFP Estimation}

The preceding literature use varying measures of firm shocks when estimating passthrough, mostly focusing on either raw value added or changes in some sort of value-added residual from an OLS regression of value added on firm characteristics. In contrast, we employ a structural model of firm production and input choice to estimate firm-level total factor productivity (TFP) which we use as our main measure of firm performance. We do this for several reasons. First, we want a measure of firm performance which robustly controls for endogeneity and transmission bias. This is important if we want to separately identify changes in capital stock or worker composition/ability from changes in firm-level productivity, while allowing these factors to be potentially correlated. Second, we want to be able to estimate productivity without placing implicit restrictions on the nature of wages or the flexibility of labor. In particular, we want to allow both employment and wages to be responsive to contemporaneous changes in firm productivity. This means we cannot, for example, assume wages perfectly reflect labor quality, or assume perfectly competitive labor markets. Our methodology, which draws heavily on recent work by Gandhi et al. (2018) (hereafter "GNR"), allows for both imperfectly competitive labor markets with adjustment costs and firm-specific wage shocks.

\subsubsection{Model and Assumptions}

Our model will be estimated on a panel of firms $j \in \mathcal{J}$, where for each firm-year pair we observe output $Y_{j t}$, capital stock $K_{j t}$, labor input $L_{j t}$ and intermediate inputs $M_{j t}$. We will be relying on several timing assumptions to identify the model.

Define $\mathcal{I}_{j t}$ as the information set available to firm $j$ when it enters period $t . \mathcal{I}_{j t}$ contains all of the information relevant to the firm (such as firm productivity) when it makes its period-t decisions. Following GNR we define any input $X_{t} \in \mathcal{I}_{j t}$ as predetermined. Any such input is thus a function of the previous period's information set: $X_{t}\left(\mathcal{I}_{j t-1}\right)$. We will treat capital as a predetermined input. Inputs which are not predetermined (and thus are set in period t) we define as variable. We define any input which is variable and where the optimal choice of $X_{t}$ is a function of lagged values of itself as dynamic. We will depart 
from GNR in assuming that labor is a dynamic input ${ }^{10}$. Finally, an input which is variable but not dynamic we define as flexible. Intermediate inputs will be treated as flexible in our framework. This implies that both $K_{j t}$ and $L_{j, t-1}$ are elements of $\mathcal{I}_{j t}$, while $L_{j t}$ and $M_{j t}$ are not.

Here we follow GNR in formally stating our assumptions on the model of firm production. Note that these assumptions are generally standard in the (recent) production function literature.

Assumption 1. The firm's production function takes the following general form in levels

$$
Y_{j t}=F\left(K_{j t}, L_{j t}, M_{j t}\right) e^{\nu_{j t}}
$$

and in logs

$$
y_{j t}=f\left(k_{j t}, \ell_{j t}, m_{j t}\right)+\nu_{j t}
$$

where $f$ is a cts and differentiable function which is strictly concave in $m_{j t}$.

Assumption 2. Capital $\left(K_{j t} \in \mathcal{I}_{j t}\right)$ is predetermined and a state variable. Labor input $\left(L_{j t} \notin \mathcal{I}_{j t}\right)$ is dynamic, such that $L_{j t-1} \in \mathcal{I}_{j t}$ is a state variable. Intermediate inputs $\left(M_{j t} \notin\right.$ $\left.\mathcal{I}_{j t}\right)$ are flexible, so that $M_{j t-1} \notin \mathcal{I}_{j t}$.

The Hicks-neutral productivity term $\nu_{j t}$ can be decomposed into a permanent component $\omega_{j t}$ which is known to the firm when it makes input decisions, and a transitory component $\varepsilon_{j t}$ which is unknown to the firm when making input decisions.

Assumption 3. The permanent productivity term $\omega_{j t} \in \mathcal{I}_{j t}$ is observed by the firm prior to making period-t decisions and is first-order Markov, such that $\mathbb{E}\left[\omega_{j t} \mid \mathcal{I}_{j t-1}\right]=\mathbb{E}\left[\omega_{j t} \mid \omega_{j t-1}\right]=$ $h\left(\omega_{j t-1}\right)$ for some continuous function $h(.) . \varepsilon_{j t} \notin \mathcal{I}_{j t}$ is i.i.d across firms and time, with $P_{\varepsilon}\left(\varepsilon_{j t} \mid \mathcal{I}_{j t}\right)=P_{\varepsilon}\left(\varepsilon_{j t}\right)$.

We normalize $\mathbb{E}\left[\varepsilon_{j t}\right]=0$ and define $\eta_{j t}=\omega_{j t}-\mathbb{E}\left[\omega_{j t} \mid \omega_{j t-1}\right]$ which implies $\mathbb{E}\left[\eta_{j t} \mid \mathcal{I}_{j t-1}\right]=0$. This gives us several measures of change in total firm productivity $\nu_{j t}=h\left(\omega_{j t-1}\right)+\eta_{j t}+\varepsilon_{j t}$. $h\left(\omega_{j t-1}\right)-\omega_{j t-1}$ is the expected and persistent change in productivity, $\eta_{j t}$ is the unexpected and persistent shock to productivity, and $\varepsilon_{j t}-\varepsilon_{j t-1}$ is the unexpected and transitory change in total productivity.

\footnotetext{
${ }^{10}$ The recent literature (see Ackerberg et al. (2015)) has argued that allowing labor to be fully flexible introduces significant identification issues. Assuming labor is fully pre-determined, as in GNR, would preclude our primary story of firms adjusting labor in response to contemporaneous firm shocks.
} 
Assumption 4. We assume that demand for intermediate input $m_{j t}=\mathcal{M}\left(k_{j t}, \ell_{j t}, \omega_{j t}\right)$ is strictly monotone in $\omega_{j t}$.

Note that this conditional (on period-t labor) demand function is critical in identifying the production function while allowing labor to be a dynamic (and not predetermined) input. It allows allows for labor adjustment costs and firm-specific wage shocks, both of which may be important in our setting ${ }^{11}$. We also make the following assumption about firm's profit maximizing behavior and environment:

Assumption 5. Firms maximize short-run expected profits and are price takers in both output and intermediate input markets. Denote the common output price index for period $t$ as $P_{t}$ and the common intermediate price index as $\rho_{t}$.

This framework gives us all of the tools to obtain robust estimates of TFP which satisfy our two main goals.

\subsubsection{Identification and Estimation Procedure}

Following GNR, assumptions 1 to 5 give us the following first order condition for firm's profit maximization problem in period t with respect to $M_{j t}$ :

$$
P_{t} \frac{\partial}{\partial M_{j t}} F\left(K_{j t}, L_{j t}, M_{j t}\right) e^{\omega_{j t}} \mathcal{E}=\rho_{t}
$$

where $\mathcal{E} \equiv \mathbb{E}\left[e^{\varepsilon_{j t}}\right]$ is a constant. Multiplying both sides by $M_{j t} / Y_{j t}$, plugging in the production function and rearranging provides our first estimating equation:

$$
\begin{aligned}
s_{j t} & =\ln \mathcal{E}+\ln D\left(k_{j t}, \ell_{j t}, m_{j t}\right)-\varepsilon_{j t} \\
& \equiv \ln \left(D^{\mathcal{E}}\left(k_{j t}, \ell_{j t}, m_{j t}\right)\right)-\varepsilon_{j t}
\end{aligned}
$$

where $s_{j t} \equiv \ln \left(\rho_{t} M_{j t} / P_{t} Y_{j t}\right)$ is the log revenue share of intermediate input expenditure and $D\left(k_{j t}, \ell_{j t}, m_{j t}\right) \equiv \frac{\partial}{\partial m_{j t}} f\left(k_{j t}, \ell_{j t}, m_{j t}\right)$ is the output elasticity of materials. Since by assumption 3 we have $\mathbb{E}\left[\varepsilon_{j t}\right]=0$, we can use equation 3 to identify $\varepsilon_{j t}$ and $D^{\mathcal{E}}$.

Given $\varepsilon_{j t}=\ln \left(D^{\mathcal{E}}\left(k_{j t}, \ell_{j t}, m_{j t}\right)\right)-s_{j t}$, we can identify the constant $\mathcal{E}=\mathbb{E}\left[\exp \left(\varepsilon_{j t}\right)\right]$, which subsequently provides the elasticity $D\left(k_{j t}, \ell_{j t}, m_{j t}\right)=D^{\mathcal{E}}\left(k_{j t}, \ell_{j t}, m_{j t}\right) / \mathcal{E}$. Once we

\footnotetext{
${ }^{11}$ See Ackerberg et al. (2015) and GNR.
} 
know $D\left(k_{j t}, \ell_{j t}, m_{j t}\right)$ and $\varepsilon_{j t}$, we can estimate the rest of the production function nonparametrically. By the fundamental theorem of calculus, we have

$$
\mathcal{D}\left(k_{j t}, \ell_{j t}, m_{j t}\right) \equiv \int \frac{\partial}{\partial m_{j t}} f\left(k_{j t}, \ell_{j t}, m_{j t}\right) d m_{j t}=f\left(k_{j t}, \ell_{j t}, m_{j t}\right)+\Psi\left(k_{j t}, \ell_{j t}\right)
$$

Define $\tilde{y}_{j t} \equiv y_{t j}-\varepsilon_{j t}-\mathcal{D}\left(k_{j t}, \ell_{j t}, m_{j t}\right)=-\Psi\left(k_{j t}, \ell_{j t}\right)+\omega_{j t}$. Plugging in the structure of $\omega_{j t}$ from assumption 3 , we get our second estimating equation:

$$
\tilde{y}_{j t}=-\Psi\left(k_{j t}, \ell_{j t}\right)+h\left(\tilde{y}_{j t-1}+\Psi\left(k_{j t-1}, \ell_{j t-1}\right)\right)+\eta_{j t}
$$

where $\tilde{y}_{j t}$ is observable given the stage-one estimates of $\varepsilon_{j t}$ and $\mathcal{D}\left(k_{j t}, \ell_{j t}, m_{j t}\right)$. Our assumptions on the firm's information set give us $\mathbb{E}\left[\eta_{j t} \mid k_{j t}, \ell_{j t-1}, k_{j t-1}, \tilde{y}_{j t-1}, \ell_{j t-2}\right]=0$, which we use with equation 5 to identify $\Psi, h$, and thus $\eta_{j t}{ }^{12}$.

Our estimation procedure follows GNR in using a standard sieve-series estimator to nonparametrically identify the input elasticity and production function. We proceed in two steps. First, we estimate the share equation with a complete 2 nd degree polynomial in $k_{j t}$, $\ell_{j t}$ and $m_{j t}$ using nonlinear least squares. This estimator solves

$$
\min _{\gamma^{\prime}} \sum_{j, t} \varepsilon_{j t}^{2}=\sum_{j, t}\left[s_{j t}-\ln \left(\sum_{r_{k}+r_{\ell}+r_{m} \leq 2} \gamma_{r_{k}, r_{\ell}, r_{m}}^{\prime} k_{j t}^{r_{k}} \ell_{j t}^{r_{\ell}} m_{j t}^{r_{m}}\right)\right]^{2}
$$

which gives us estimates of $\hat{\varepsilon_{j t}}$ and $\widehat{D^{\mathcal{E}}}\left(k_{j t}, \ell_{j t}, m_{j t}\right)=\sum_{r_{k}+r_{\ell}+r_{m} \leq 2}\left(\hat{\gamma}_{r_{k}, r_{\ell}, r_{m}}^{\prime} k_{j t}^{r_{k}} \ell_{j t}^{r_{\ell}} m_{j t}^{r_{m}}\right)$. We can then recover $\widehat{\mathcal{E}}=\mathbb{E}\left[\exp \left(\hat{\varepsilon}_{j t}\right)\right]$ and the input elasticity

$$
\widehat{D}\left(k_{j t}, \ell_{j t}, m_{j t}\right)=\sum_{r_{k}+r_{\ell}+r_{m} \leq 2}\left(\hat{\gamma}_{r_{k}, r_{\ell}, r_{m}} k_{j t}^{r_{k}} \ell_{j t}^{r_{\ell}} m_{j t}^{r_{m}}\right)
$$

where $\hat{\gamma} \equiv \hat{\gamma}^{\prime} / \widehat{\mathcal{E}}$. We then integrate the estimated flexible input elasticity up to recover

$$
\widehat{\mathcal{D}}\left(k_{j t}, \ell_{j t}, m_{j t}\right)=\sum_{r_{k}+r_{\ell}+r_{m} \leq 2}\left(\frac{m_{j t}}{r_{m}+1} \hat{\gamma}_{r_{k}, r_{\ell}, r_{m}} k_{j t}^{r_{k}} \ell_{j t}^{r_{\ell}} m_{j t}^{r_{m}}\right)
$$

which allows us to recover $\hat{\tilde{y}}_{j t}=y_{j t}-\hat{\varepsilon}_{j t}-\widehat{\mathcal{D}}\left(k_{j t}, \ell_{j t}, m_{j t}\right)$. In the second step, we estimate equation 5 using GMM, where we similarly approximate $\Psi\left(k_{j t}, \ell_{j t}\right)$ using a complete 2 nd degree polynomial and $h\left(\omega_{j t-1}\right)$ as a 1st degree (linear) polynomial, implying that persistent

\footnotetext{
${ }^{12}$ This differs from GNR, who assume that labor is predetermined. We relax this assumption since we want to allow firms to adjust labor in response to persistent shocks in productivity $\left(\eta_{j t}\right)$.
} 
TFP follows an AR(1) process. Since we can identify both the constant of integration and TFP only up to an additive constant, we follow GNR in normalizing $\Psi$ to be mean zero and so allow the constant to show up in the level of productivity. This gives us the following second-stage estimating equation:

$$
\tilde{y}_{j t}=-\sum_{0<\tau_{k}+\tau_{\ell} \leq 2} \alpha_{\tau_{k}, \tau_{\ell}} k_{j t}^{\tau_{k}} \ell_{t j}^{\tau_{\ell}}+\sum_{0 \leq a \leq 1} \delta_{a}\left(\tilde{y}_{j t-1}+\sum_{0<\tau_{k}+\tau_{\ell} \leq 2} \alpha_{\tau_{k}, \tau_{\ell}} k_{j t-1}^{\tau_{k}} \ell_{t j-1}^{\tau_{\ell}}\right)^{a}+\eta_{j t}
$$

Since $\mathbb{E}\left[\eta_{j t} \mid k_{j t}, \ell_{j t-1}, \mathcal{I}_{j t-1}\right]=0$, the only endogenous variable is $\ell_{j t}$. Thus we can use functions of the set $\left\{k_{j t}, k_{j t-1}, \ell_{j t-1}, \ell_{j t-2}, m_{j t-1}, \tilde{y}_{j t-1}\right\}$ as instruments. In particular, our moments are $\mathbb{E}\left[\eta_{j t} \tilde{y}_{j t-1}^{a}\right]$ and $\mathbb{E}\left[\eta_{j t} k_{j t}^{\tau_{k}} \ell_{j t-2}^{\tau_{\ell}}\right]$ for all $0 \leq a \leq 1$ and $0<\tau_{k}+\tau_{\ell} \leq 2$, leaving us exactly identified ${ }^{13}$.

This provides us with estimates of the production function parameters as well as $\hat{\omega}_{j t}, \hat{\eta}_{j t}$ and $\hat{\bar{\omega}}_{j t} \equiv \hat{h}\left(\hat{\omega}_{j t-1}\right)=\hat{\delta}_{0}+\hat{\delta}_{1} \hat{\omega}_{j t-1}$.

\subsection{Selection Model}

Our primary goal is to separately estimate the effects of TFP changes on workers' wage growth for workers who stay in their firms, and for workers who switch between firms. However, our analysis is likely subject to selection bias, since workers who choose to stay at the firm between periods $t-1$ and $t$ may tend to experience more or less passthrough than those who left would have experienced if they stayed. For example, suppose firms pass negative shocks to workers as productivity decreases. Those workers who recieve a large wage drop may choose to leave the firm, which would tend to bias estimates of negative passthrough towards zero if one solely analyzes stayers. There may also be selection on the firm side, as firms which experience large negative productivity shocks may choose to exit the market. If these are the firms which tend to have more passthrough, then the estimates of passthrough may be biased. This issue has been mentioned by the previous literature on passthrough (see for example Guiso et al. (2005)), however, to our knowledge, we are the first to correct for selection on either the worker or firm side in the passthrough literature.

To correct for selection bias we adopt a simple model to describe job stayers's selection

\footnotetext{
${ }^{13}$ As pointed out by GNR, this implies that the estimator is a sieve-M estimator, which allows us to do inference treating the polynomials as if they were the true parametric structure.
} 
problem as given by

$$
\begin{array}{rlrl}
\Delta \log w_{i j t} & =\mathbb{X}_{i j t} \beta+\nu_{i j t} & & \text { if } u_{i j t}>0, \\
\Delta \log w_{i j t} & =\text { unobserved } & & \text { if } u_{i j t} \leq 0, \\
u_{i j t} & =Z_{i j t} \delta+\xi_{i j t}, & & \\
D_{i j t} & =1 & \text { if } u_{i j t}>0, \\
D_{i j t} & =0 & \text { if } u_{i j t} \leq 0 .
\end{array}
$$

Here $u_{i j t}$ denotes the net utility that a worker gets when she chooses to stay at firm $j$ at time $t$ as opposed to switching to a different firm or out of employment; $w_{i j t}, \mathbb{X}_{i j t}, Z_{i j t}$ are stayers' wage, observable firm/workers characteristics which affect workers' wage growth (from equation 1), and observable characteristics which affect the utility of staying in their job, respectively. When the net utility from staying in their firm is below 0, workers switch out, so we are not be able to observe their within-firm wage change and thus passthrough. We denote whether or not we observe the stayer's wage change by the indicator variable $D_{i j t}$.

Our strategy to correct for the selection problem follows Heckman (1979). Specifically, we assume that the joint distribution for the errors is given by:

$$
\left(\begin{array}{l}
\nu_{i j t} \\
\xi_{i j t}
\end{array}\right) \sim \mathbb{N}\left[\left(\begin{array}{l}
0 \\
0
\end{array}\right),\left(\begin{array}{cc}
\sigma^{2} & \rho \sigma \\
\rho \sigma & 1
\end{array}\right)\right]
$$

Given this assumption, we estimate a first-stage probit regression of the probability that a given worker stays at her firm as a function of $Z_{i j t}$, obtaining $\hat{\delta}$. Then we calculate the fitted value of the latent variable $\hat{u}_{i j t}$ and compute the inverse Mills ratio $\hat{\lambda}_{i j t}$ as a function of $\hat{u}_{i j t}$. Finally we include $\hat{\lambda}_{i j t}$ in the second stage regression and get a consistent and unbiased (though not asymptotically efficient) estimator of $\beta$.

Our identification strategy then relies on having a reasonable exclusion restriction for the first stage, in that we can include some firm and worker variation which plays a role in the probability that workers will stay or leave their firm, but do not affect the growth rate of workers' wages should they choose to stay at the firm that period. In order to do this, we use the spousal linkage data to create, for each worker, a set of marital status indicators and for those with working spouses - measures of their spouses employment status. Specifically, we include indicators for marriage status, separation, change of spouse and whether or not 
the individual's spouse is working if married. This last term is interacted with other spousal information including log wage, change in log wage, firm TFP and log TFP change, age, experience, and whether or not the spouse is a stayer for that period. We exclude spousal working information if the couple is working at the same firm. The assumption for our instrument is that when a worker is getting married/divorced or if his/her spouse has an income change or other employment shock, this will affect the worker's decision on whether or not to keep working at the current firm. However, changes in marriage status, spousal employment,or spousal wages should not affect the worker's wage growth at his/her current firm conditional on staying, unless the couple are working at the same firm. To control for firm selection, we also include in $Z_{i j t}$ various firm-level variables such as financial information and lags of TFP which shouldn't directly affect within-firm worker wage growth conditional on the set of observables in equation 1.

\section{Baseline Results}

\subsection{Non-Parametric Analysis}

We start our analysis by discussing the relation between changes in firm-level productivity and workers' wage growth using a simple, non parametric approach. For doing that, we pool our sample of firms and individuals between 2002 and 2012 and we sort firms by their total productivity growth in one hundred bins. Then, within each bin, we calculate different moments of the wage growth distribution: the mean, the standard deviation, and the 90th, 50 th, and 10th percentiles. Moments are weighted by firm's employment so as to reflect the underlying firm size distribution within each bin.

The left panel of figure 3 shows the average wage growth within each bin of the TFP growth distribution. Three aspects of the plot are worth noticing. First, the average wage growth is remarkably stable from the first percentiles of the distribution - where the typical firm experiences a large decline in TFP - up to the 80th percentile of the distribution. This suggests that most firms provide insurance to their workers from changes in firm-level productivity. Second, the average wage growth increases dramatically as we move above the fifth quintile of the TFP growth distribution. The typical firm above the 80th percentile of the TFP growth distribution experiences an increase of TFP of $25 \%$ which translates into an average wage growth of $20 \%$ for the workers of these firms. Finally, considering how flat the relation between wage growth and TFP growth is across most of the TFP growth 
Figure 3: Average Wage Growth Across the TFP Growth Distribution
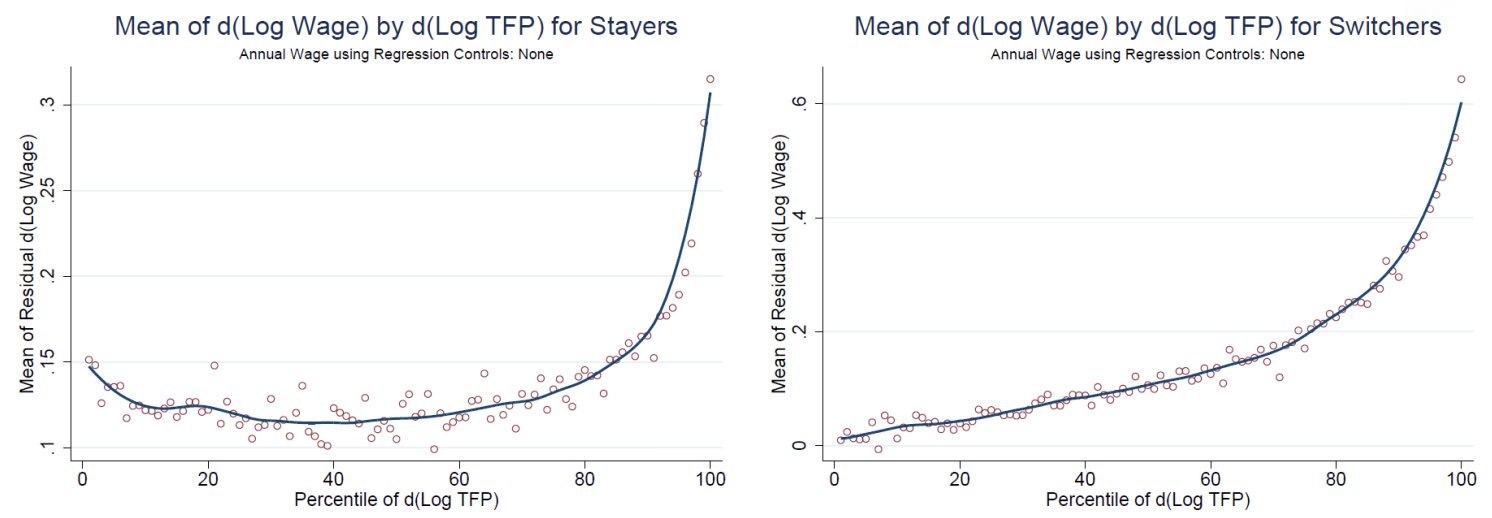

Note: The left panel of figure 3 shows the employment weighted average of the workers' wage growth distribution within each percentile of the TFP growth distribution for a sample of workers that stay in the same firm for two consecutive period. The right panel displays the same statistic for the set of worker that switch firms between two consecutive periods.

distribution, it is not surprising that most papers in the literature find very small average passthrough from TFP to wages.

How does wage growth vary for workers that switch between firms? To provide a first answer to this question, the right panel of figure 3 repeats the previous analysis by calculating the average wage growth for switchers within each percentile of the TFP growth distribution. Importantly, the TFP growth percentiles in the $\mathrm{x}$-axis in both plots of figure 3 are the same so we can directly compare them. Still, the interpretation of a TFP change is slightly different. In the left panel, a TFP change reflects the change in the productivity of the same firm across time whereas in the right panel, a TFP change reflects the gap in productivity between two different firms across time. We discuss and control for this in the analysis below. The right panel of figure 3 shows two important results, first, workers that move between firms whose TFP differential implies a growth rate at the left tail of the TFP growth distribution obtain almost no wage growth. Moreover, these workers observe lower wage growth than the average worker that stays in the same firm conditional on the firm experiencing the same decline in TFP. Second, workers that move to more productive firms do experience a wage growth, which is higher than the wage growth of workers that stay in the same firm conditional on the firm observing the same TFP growth. In fact, the average wage growth for stayers and switchers crosses at around the 40th percentile of the TFP growth distribution.

We also find significant differences in the dispersion of wage growth across the TFP 
Figure 4: Dispersion of Wage Growth Across the TFP Growth Distribution
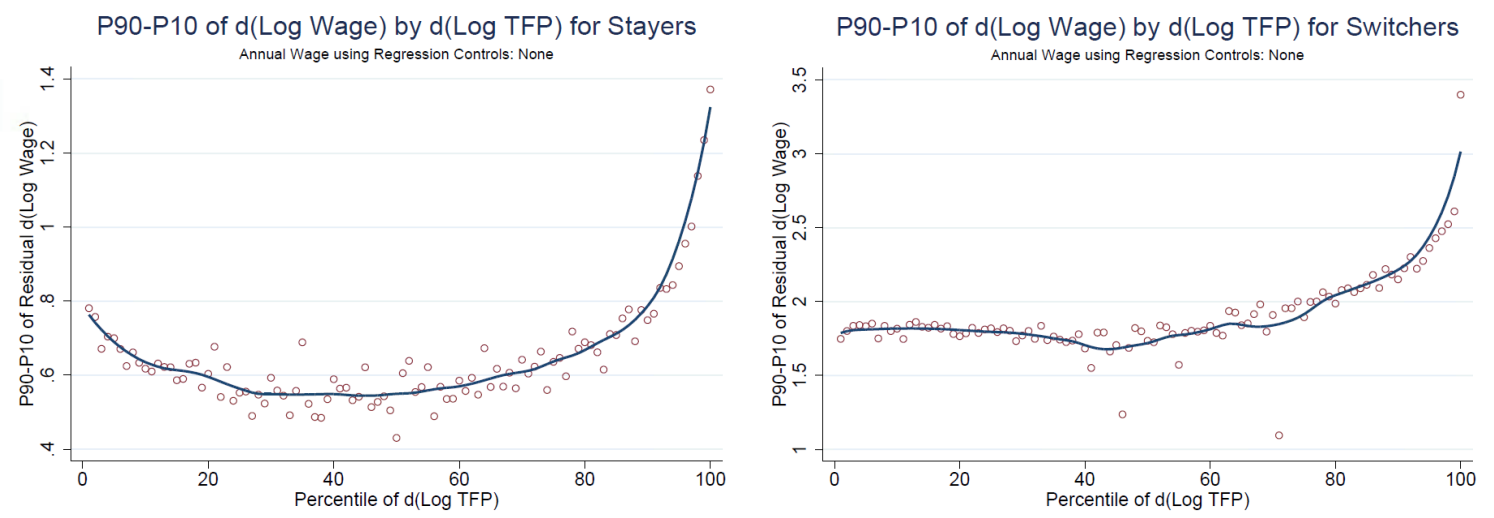

Note: The left panel of figure 4 shows the employment weighted 90th-to-10th percentiles spread of the workers' wage growth distribution within each percentile of the TFP growth distribution for a sample of workers that stay in the same firm for two consecutive period. The right panel displays the same statistic for the set of worker that switch firms between two consecutive periods.

growth distribution. In fact, firms at the top and bottom of the distribution of TFP growth command higher wage growth dispersion for their workers relative to firms in the middle of distribution. To see this, the left panel (right panel) of figure 4 shows the 90th-to-10th percentiles spread of the wage growth distribution within different percentiles of the TFP growth distribution for workers that stay in the same firm (switch across firms). The figure shows a marked u-shaped pattern with more dispersion at the top and bottom. In fact, dispersion of wage growth at lower percentiles of the TFP growth distribution is almost 30 percentage points higher than the dispersion of wage growth among workers in firms at the middle of the TFP growth distribution. The difference is even more stark between workers in the middle and at the top of the TFP growth distribution: relative to the middle of the distribution, dispersion of wage growth almost doubles at the highest percentiles of the TFP growth distribution.

Are these differences in dispersion across the TFP distribution the results of workers receiving higher wage losses or higher wage gains after a change in firms' TFP? To answer this question we separate the 90th-to-10th percentiles spread between the part that comes from the left tail, the 50th-to-10th percentiles differential, from the part that comes from the right tail of the distribution, the 90th-to-50th percentiles spread. The results for stayers are shown in figure 5 .

Notice that both measures of dispersion show a u-shaped pattern, indicating large left 
Figure 5: Right and Left Tail Dispersion of Wage Growth Across the TFP Growth Distribution
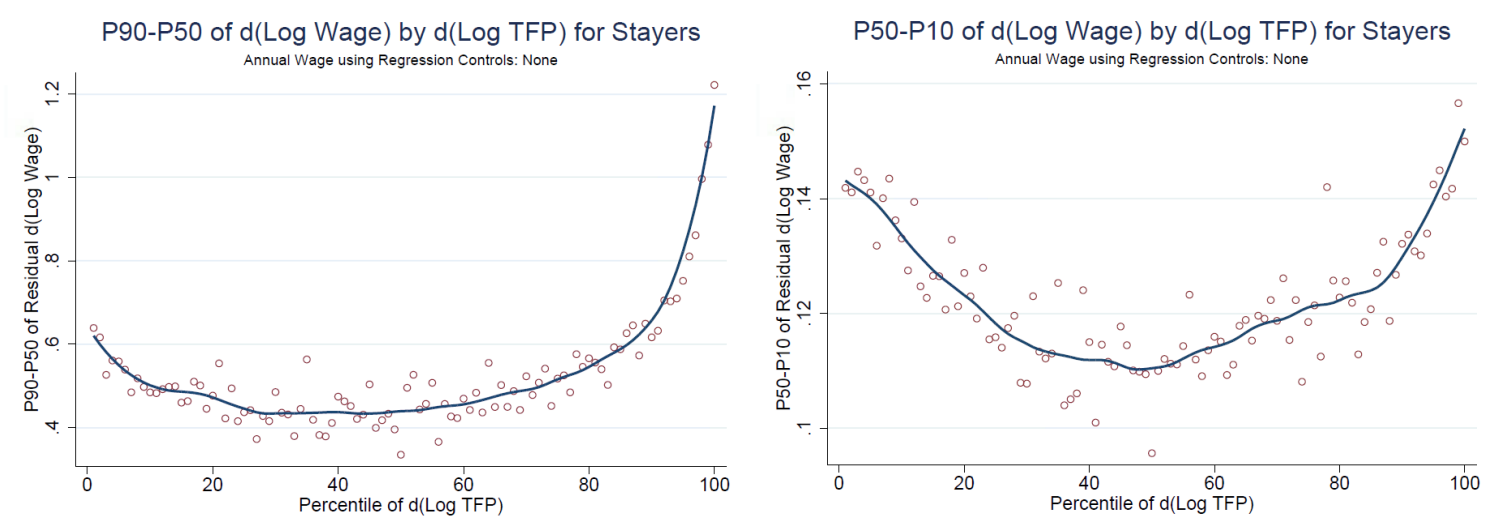

Note: The left panel of figure 5 shows the employment weighted 90th-to-50th percentiles spread of the workers' wage growth distribution within each percentile of the TFP growth distribution for a sample of workers that stay in the same firm for two consecutive period. The right panel displays the the employment weighted 50th-to-10th percentiles spread for the same sample of workers.

and right tail dispersion of wage growth at the tails of the TFP growth distribution. Second, the 90th-to-50th percentiles spread is almost 5 times the 50th-to-10th percentile spread, indicating that workers are more likely to experience positive than negative changes in their wages conditional on a change in firms' TFP. As we show later in our regression analysis, this is also true when conditioning for firm and worker observable characteristics. Furthermore, the fact that most of the dispersion is accounted for by the right tail indicates that the wage growth distribution for stayers is right skewed, a feature that has been also observed for other countries and datasets (see for instance Guvenen et al. (2015)). We find similar patterns for switchers, indicating that most of the workers see positive annual changes in their income, independently of the position of the firm in the TFP growth distribution.

In summary, our simple non parametric analysis shows a substantial heterogeneity of wage growth across firms and positive relation between productivity growth and wage growth. Still, this heterogeneity can be the product of differences across workers, across firms, and over time, which cannot be easily captured by the simple setting we have discussed. Moreover, selection of workers and firms into different groups might impact our results. In the following section we control for observable characteristics of stayers and switchers to show that passthrough is positive and economically significant. 


\subsection{Regression Analysis}

In this subsection we analyze the passthrough of firms' shocks to workers' wage growth. We focus on a simple regression analysis for two reasons. First, this simple approach is similar to what has been used in the previous literature, allowing us to more directly compare our results with other papers. Second, we aim to highlight that even if one puts aside selection considerations, the passthrough from TFP shocks to workers' wages is positive and economically significant.

As described in section 3, our baseline analysis is based in a series of OLS panel regressions of the form,

$$
\Delta \log w_{i j t}=\alpha+\beta^{\eta} \eta_{i j t}+\beta^{\varepsilon} \varepsilon_{i j t}+\mathbb{Z}_{j t}^{\prime} \gamma+X_{i t}^{\prime} \lambda+\delta_{t}+\epsilon_{i j t}
$$

where the main coefficients of interest are $\beta^{\eta}$ and $\beta^{\varepsilon}$, the elasticity of wages to changes in persistent and transitory firm-level productivity. In this section we restrict our sample to stayers, who are workers employed at the same firm in periods $t-1$ and $t$.

Table 2 shows our first set of results. Column (1) shows that the passthrough from TFP growth to wage growth is positive and statistically significant for stayers. This is true for both the persistent component of the TFP shock as well as the transitory component. The baseline result indicates that a one standard deviation innovation in the permanent component of firm TFP implies a change in annual income of around \$251 USD for a worker making the average wage of that subsample. A one standard deviation transitory innovation in firmlevel TFP implies a change in annual income of around US\$792. Together they represent $2 \%$ of the overall income per capita in Denmark. Considering that in any given year around $33 \%$ of firms (which employ around $40 \%$ of all the workers in the economy) receive either a persistent or transitory productivity shock that is at least one standard deviation away from the mean ( $6 \%$ of firms and $8 \%$ of workers experience both), this represents a significant aggregate change in income.

Does the sign of the change in TFP matter for the passthrough from TFP to wages? To answer this question we separate workers employed by firms experiencing a negative productivity change from those workers in firms experiencing a positive productivity change. We then run the same specification in equation (1) within each group of workers. Columns (2) and (3) of table 2 show the results. First, notice in column (2) that the coefficient on negative permanent TFP shock changes to basically zero and is not statistically significant, suggesting that firms insulate workers from negative shocks to persistent productivity. Col- 
Table 2: Passthrough Regressions

\begin{tabular}{ccccccc}
\hline & \multicolumn{3}{c}{ Baseline } & \multicolumn{3}{c}{ Corrected } \\
& $(1)$ & $(2)$ & $(3)$ & $(4)$ & $(5)$ & $(6)$ \\
& $\Delta T F P_{j t}$ & $-\Delta T F P_{j t}$ & $+\Delta T F P_{j t}$ & $\Delta T F P_{j t}$ & $-\Delta T F P_{j t}$ & $+\Delta T F P_{j t}$ \\
\hline & & & & & & \\
Persistent $\left(\beta^{\eta}\right)$ & $0.016^{* * *}$ & 0.001 & $0.044^{* * *}$ & $0.045^{* * *}$ & $0.035^{* * *}$ & $0.088^{* * *}$ \\
& $(0.004)$ & $(0.004)$ & $(0.009)$ & $(0.005)$ & $(0.006)$ & $(0.008)$ \\
& & & & & \\
Transitory $\left(\beta^{\varepsilon}\right)$ & $0.041^{* * *}$ & $0.035^{* * *}$ & $0.056^{* * *}$ & $0.042^{* * *}$ & $0.033^{* * *}$ & $0.057^{* * *}$ \\
& $(0.005)$ & $(0.003)$ & $(0.013)$ & $(0.005)$ & $(0.003)$ & $(0.013)$ \\
& & & & & & \\
\hline \$Value $\left(\beta^{\eta}\right)$ & $\$ 251$ & $\$ 16$ & $\$ 671$ & $\$ 705$ & $\$ 537$ & $\$ 1,326$ \\
\% Value $\left(\beta^{\varepsilon}\right)$ & $\$ 792$ & $\$ 690$ & $\$ 1053$ & $\$ 812$ & $\$ 624$ & $\$ 1,059$ \\
$\%$ of Income $\left(\beta^{\eta}\right)$ & $0.5 \%$ & $0.0 \%$ & $1.3 \%$ & $1.4 \%$ & $1.1 \%$ & $2.6 \%$ \\
\hline
\end{tabular}

Note: Table 2 shows a set of OLS panel regressions controlling for firm and worker characteristics. In each column, the dependent variable is the growth rate of real wages for individuals that stay in the same firm for two consecutive periods. From columns (1) to (3) the main explanatory variable is the change in firm-level (log) TFP. In column (4) the main explanatory variable is the change in the firm-level $(\mathrm{log})$ value added. The row named \$Value shows the change in real (USD) wages resulting from a one standard deviation shock to TFP for a worker with the average wage for that group. $* p<0.1, * * p<0.05, * * * p<0.01$. Robust standard errors, below the point estimates, are clustered at the firm level.

umn (3) however, shows a significant and positive correlation between positive shocks to persistent TFP and wage growth, indicating that firms pass a fraction of positive changes in productivity to wages. In monetary values, a change in permanent TFP shock of one standard deviation, conditional on this change being negative, translates into a decline in annual labor earnings of only $\$ 16$ for a worker with the average wage in that group, whereas a positive change in TFP translates into an increase in annual labor earnings of $\$ 671$ for that same worker. The effect of transitory TFP shocks on wages is significant for both negative and positive shocks, showing a similar asymmetric effect to the persistent shocks.

The positive but small relationship between negative changes in TFP and wage growth that we find falls in line with results found in other papers (see for instance Juhn et al. (2018) and Rute Cardoso and Portela (2009)). These results are based on the sample of workers that stay in the same firm for two consecutive periods. However, these regression results might be biased by the presence of selection into the status of "stayer". We discuss this in the next section and implement a simple method to correct for the effect of selection on the passthrough coefficients. 


\subsection{Selection Bias}

We postulated in section 3.4 that our results might be heavily effected by selection bias. This problem arises because the sample considered in the first three columns of table 2 is defined only for workers who have stayed at their firm, neglecting the possibility that the probability of staying may be correlated with passthrough and expected change in wages. In Appendix A, we investigate the effect of firm productivity shocks on the probability of worker entry and exit, confirming that firm-level tfp shocks do drive worker flows in and out of the firm. The direction of the bias, however, is not ex-ante clear. For instance, after a negative productivity shock firms might decide not to reduce wages but lay off some workers to reduce labor costs. Since these workers are not counted as stayers, we do not consider the effect of changes in TFP on their wages, effectively reducing the measured impact of negative changes of productivity on wages. Workers who are most exposed to or expect large passthrough from negative shocks may also voluntarily choose to leave the firm. Similarly, the effect of positive productivity shocks might be downward biased. Workers facing large passthrough effects from a positive TFP shock may be very high skilled workers who are more likely to be poached by, or leave for, other firms. In this section we make some progress in controlling for selection using the simple Heckman selection method outlined in section 3.4.

Columns (4) to (6) of table 2 show that the results of persistent shocks after correcting for selection are very different. First of all, the coefficient for $\Delta T F P_{i j t}$ in column (5) almost triples in magnitude relative to the impact of persistent TFP shocks on wages when one does not control for selection (column (1) of table 2). The selection-corrected results imply that a worker in a firm that experiences a one standard deviation persistent shock to TFP will receive an average increase in her annual earnings of $\$ 705$, or $1.4 \%$ of the average annual income. This increase in the passthrough from firms' productivity to workers' wages points to a much smaller role for the firm as a source of insurance for the worker. This holds true for both positive and negative shocks. Starting from column (5), the effect of a negative productivity change goes from being near zero in column (2) to 0.035 in column (6) and it becomes statistically significant. This implies that a worker in a firm receiving a negative permanent productivity shock of one standard deviation sees his annual income reduced by $\$ 537$, a value that is much larger relative to the value measured when one does not control for selection. We also find a significant increase in the effect of a positive permanent productivity shock into wages as it is shown in column (6) of table 2. In this case, a positive persistent productivity shock of one standard deviation commands an increase in wages of more than $\$ 1,000$, that is, almost $2.6 \%$ of the average income per capita. 
There are several main conclusions we can draw from these results. First, there is asymmetry in worker exposure to firm-level TFP shocks. Firms appear to pass positive shocks through to workers more than they do negative shocks, providing some insurance against downward movements in wages. Second, it seems that the selection effect tends to bias the estimated passthrough coefficients downwards on average, as both the overall and negative shock passthrough coefficients increased dramatically after correcting for selection. This confirms our intuition that both workers and firms may exit when faced with big negative tfp shocks or threats of significant negative passthrough. However, there is also a positive selection bias, with the effect of a positive shock doubling after correction. This is possibly due to better workers at firms experiencing tfp growth leaving for better opportunities. The transitory shock component, however, is not affected when correcting for the selection bias. This is intuitive and fits with the underlying model of firm optimization - firms and workers make their employment decisions in period $t$ with information on the persistent shock to $\operatorname{tfp} \eta_{j t}$, but not the transitory shock $\varepsilon_{j t}$. Workers can not ex-ante predict and react to the transitory component of TFP, so selection has almost no effect on the transitory shock coefficient.

To sum up, firms TFP shocks have a sizable and significant passthrough effect on worker wage growth. After carefully correcting for selection bias, the joint effects of TFP shocks on wage growth is much bigger than commonly found in the literature. To put into context, a one standard deviation shock to both the permanent and transitory component is associated with a more than $\$ 1,500$ change annual income for a worker with the average wage, or $3 \%$ of per capita income. Importantly, passthrough is not symmetric: firms pass more of their positive persistent and transitory shocks on to workers than their negative shocks. However, negative passthrough is significant and not negligible - firms are not providing full insurance or near full insurance to workers when they encounter a negative TFP shock.

\section{$5 \quad$ Heterogeneous Passthrough}

In this section we study how the passthrough from changes in firm TFP to worker wage growth varies across the distribution of worker and firm types. We focus on how passthrough differs across worker age and income levels, across firm productivity levels, and across the business cycle. We also investigate how wages are affected for workers moving between firms of differing productivity. 


\subsection{High vs. Low Wage Workers}

We first study how passthrough from firm shocks to worker wages varies across workers of different income levels. We split our sample of stayers into two groups. First, we classify workers in a given year as "low income" if their labor earnings are below the 20th percentile of the labor earnings distribution in that year and we classify workers as "high income" if their labor earnings are above the 80th percentile for that year. We then estimate the effect of shocks to firm TFP on wages within each of these groups, correcting for selection as described in section 4.3 .

The results both with and without selection correction are shown in table 3. The differences between low and high wage workers are staggering: selection issues aside, the response of wages to changes in firm-level TFP are, on average, much higher for high wage workers relative to low wage workers. For instance, comparing columns (1) and (4) of panel B in table 3 we see that a change in TFP of one standard deviation implies a change in worker earnings of about $\$ 2,000$ more if the individual is a high wage worker relative to a low wage worker. Even after considering that high wage workers receive labor earnings that are in average two-times higher than the income of low wage workers, the effect on high wage workers is still much bigger. In fact, a change in income associated with one standard deviation of permanent TFP shock is about 3.3\% in the annual earnings for high wage workers compare to $2.0 \%$ annual earnings for low wage workers. ${ }^{14}$ We also find large differences when comparing the effects of positive and negative shocks. Looking at columns (2) and (3) for instance, we see that the elasticity of negative shocks is roughly two thirds the wage elasticity for positive shocks among high wage workers after taking selection into account. We observe similar results for low wage workers. As before, selection has an important impact on the estimates, more so for negative shocks and for high wage workers - who also appear to be significantly more exposed to income risk due to negative firm shocks than low wage workers.

Note that for both high wage worker and low wage workers, the passthrough effect from persistent TFP shocks to wage growth is much higher than it is for average wage workers (column 4 to 6 in table 2). This is because the middle wage workers whose income ranges from the 20 to 80 percentiles are the least sensitive to firm TFP shocks. As suggested in section 4.1, the sensitivity of workers' income changes to firm shocks is U-shaped with a big jump at the very top. Workers whose income is in the middle are much more insured against firm productivity shocks. This could be due to the nature of the wage contracts at

\footnotetext{
${ }^{14}$ Real average annual income for high wage workers is around $\$ 85,000$ whereas for low wage workers is around $\$ 35,000$.
} 
Table 3: Passthrough Regressions for High and Low Wage Workers

\begin{tabular}{|c|c|c|c|c|c|c|}
\hline & (1) & $(2)$ & $(3)$ & (4) & $(5)$ & (6) \\
\hline & \multicolumn{3}{|c|}{ High Wage Workers } & \multicolumn{3}{|c|}{ Low Wage Workers } \\
\hline & $\Delta T F P_{j t}$ & $-\Delta T F P_{j t}$ & $+\Delta T F P_{j t}$ & $\Delta T F P_{j t}$ & $-\Delta T F P_{j t}$ & $+\Delta T F P_{j t}$ \\
\hline $\mathrm{A}$ & \multicolumn{6}{|c|}{ Uncorrected } \\
\hline Persistent $\left(\beta^{\eta}\right)$ & $0.030^{* * *}$ & $0.024^{* * *}$ & $0.050^{* * *}$ & $0.011^{* * *}$ & $-0.011^{* * *}$ & $0.033^{* * *}$ \\
\hline Transitory $\left(\beta^{\varepsilon}\right)$ & $0.057^{* * *}$ & 0.053 & $0.077^{* * *}$ & $0.043^{* * *}$ & $0.041^{* * *}$ & $0.046^{* * *}$ \\
\hline$\$$ Value $\left(\beta^{\eta}\right)$ & $\$ 738$ & $\$ 587$ & $\$ 1,208$ & $\$ 101$ & $\$-101$ & $\$ 286$ \\
\hline$\%$ of Income $\left(\beta^{\eta}\right)$ & $1.0 \%$ & $1.0 \%$ & $1.5 \%$ & $0.3 \%$ & $0.3 \%$ & $1.0 \%$ \\
\hline $\mathrm{B}$ & \multicolumn{6}{|c|}{ Corrected } \\
\hline Persistent $\left(\beta^{\eta}\right)$ & $0.109^{* * *}$ & $0.110^{* * *}$ & $0.154^{* * *}$ & $0.067^{* * *}$ & $0.047^{* * *}$ & $0.096^{* * *}$ \\
\hline Transitory $\left(\beta^{\varepsilon}\right)$ & $0.058^{* * *}$ & $0.044^{* * *}$ & $0.080^{* * *}$ & $0.045^{* * *}$ & $0.042^{* * *}$ & $0.047^{* * *}$ \\
\hline$\$$ Value $\left(\beta^{\eta}\right)$ & $\$ 2,669$ & $\$ 2,702$ & $\$ 3,759$ & $\$ 621$ & $\$ 436$ & $\$ 873$ \\
\hline$\%$ of Income $\left(\beta^{\eta}\right)$ & $3.3 \%$ & $3.3 \%$ & $4.6 \%$ & $2.0 \%$ & $1.4 \%$ & $2.9 \%$ \\
\hline
\end{tabular}

Note: Table 3 shows a set of panel regressions controlling for firm and worker characteristics. In each column, the dependent variable is the growth rate of real wages for individuals that stay in the same firm for two consecutive periods. The main explanatory variables are estimated shocks to the transitory and persistent components of firm-level (log) TFP. The row named Value (USD) shows the change in real wages resulting from a one standard deviation shock to TFP for a worker with the average wage for that group. The top panel shows estimates without correcting for selection while the bottom panel shows selection-corrected estimates. High wage: top $20 \%$ of wage distribution; Low wage: bottom $20 \%$ of wage distribution. $* p<0.1, * * p<0.05, * * * p<0.01$. Robust standard errors are clustered at the firm level.

high/low vs. average wage jobs, where for example, high paid jobs may have wages which are more contingent on firm performance than mid-range jobs in manufacturing where wage contracts are more rigid. Finally, similar with the baseline results, the effect of transitory TFP shocks on wage growth is not so different before or after the correction for selection bias. Furthermore, the level of transitory shock passthrough is similar for high wage and low wage workers, suggesting that heterogeneity in passthrough from shocks to persistent TFP is driven by something more deliberate and systematic than passthrough from transitory shocks.

\section{$5.2 \quad$ Younger and Older Workers}

Workers may be more or less exposed to firm TFP shocks depending on their age. One might expect that older workers are likely to be more experienced on average or have greater tenure and therefore are potentially more insured by firms than workers who have just entered the 
Table 4: Passthrough Regressions for Younger and Older Wage Workers

\begin{tabular}{ccccccc}
\hline & $(1)$ & $(2)$ & $(3)$ & $(4)$ & $(5)$ & $(6)$ \\
& \multicolumn{3}{c}{ Young Workers } & \multicolumn{3}{c}{ Old Workers } \\
& $\Delta T F P_{j t}$ & $-\Delta T F P_{j t}$ & $+\Delta T F P_{j t}$ & $\Delta T F P_{j t}$ & $-\Delta T F P_{j t}$ & $+\Delta T F P_{j t}$ \\
\hline Persistent $\left(\beta^{\eta}\right)$ & $0.116^{* * *}$ & $0.114^{* * *}$ & $0.205^{* * *}$ & $0.041^{* * *}$ & $0.031^{* * *}$ & $0.074^{* * *}$ \\
& & & & & & \\
Transitory $\left(\beta^{\varepsilon}\right)$ & $0.050^{* * *}$ & $0.040^{* * *}$ & $0.060^{* * *}$ & $0.039^{* * *}$ & $0.028^{* * *}$ & $0.059^{* * *}$ \\
& & & & & & \\
\hline Value (USD) $\left(\beta^{\eta}\right)$ & $\$ 1,594$ & $\$ 1,590$ & $\$ 2,702$ & $\$ 654$ & $\$ 520$ & $\$ 1,158$ \\
$\%$ of Income $\left(\beta^{\eta}\right)$ & $3.5 \%$ & $3.4 \%$ & $6.2 \%$ & $1.2 \%$ & $1.0 \%$ & $2.2 \%$ \\
\hline \hline
\end{tabular}

Note: Table 4 shows a set of panel regressions controlling for firm and worker characteristics. In each column, the dependent variable is the growth rate of real wages for individuals that stay in the same firm for two consecutive periods. The main explanatory variables are estimated shocks to the transitory and persistent components of firm-level (log) TFP. The row named Value (USD) shows the change in real (USD) wages resulting from a one standard deviation shock to TFP for a worker with the average wage for that group. Young Workers: $\leq 35$ years old; Old Workers: $>50$ years old. $* p<0.1, * * p<0.05, * * * p<0.01$. Robust standard errors are clustered at the firm level.

firm. Differences in passthrough across age may also be due to age-related selection into high or low passthrough firms, industries or occupations. We divide our sample of workers by age, and define workers who are younger than 35 years old as "young workers", and define workers who are older than 50 as "old workers". The results are shown in table 4. In this analysis we only show the effects of TFP shocks after correcting for the selection bias. As expected, the effect of persistent TFP shocks on wage growth is stronger for younger workers than older workers. The passthrough elasticity for younger workers is almost three times that for older workers. In dollars, the average younger worker experiences a more than $\$ 1,500$ dollar wage change from a one standard deviation shock to persistent TFP, while for older workers, this number is $\$ 654$. This is an especially large effect for younger workers considering that their average annual wage is almost $\$ 10,000$ dollars lower than for older workers. Similar with previous results, workers are relatively more sheltered from negative shocks than from positive shocks, but negative passthrough is still significant and non-negligible. As we found with high and low wage workers, there is not nearly as much heterogeneity in transitory shock passthrough as there is for persistent shock passthrough, though passthrough from transitory shocks are still economically and statistically significant.

\subsection{Switchers and Stayers}

So far we have focused on the effect of TFP shocks on stayers, that is, workers that maintain a stable employment relationship with a firm for the two years over which the change in TFP 
is calculated. This is a natural starting point as changes in wages for stayers can be tied more easily to changes in firm productivity and concepts of insurance against firm-level risk. Moreover, this is the group of workers that the literature has analyzed more often, ignoring the effect of firm shocks on the wages of workers that move between firms. In this section we extend the existing literature to take into account the effect of idiosyncratic, firm and worker-level, productivity changes on the wages of those workers that move across different employers. This is a large group of workers: in a particular year, around $20 \%$ of Danish workers have changed employer the following year. Unfortunately, our data does not allow us to directly distinguish between an individual who passed through an unemployment spell prior to joining a different employer or had a direct transition between employers. Therefore, we will put aside issues related to voluntary or involuntary separations and we will treat all workers who make annual employment-to-employment transitions the same.

Similar to the previous section, we run a set of OLS panel regressions in which the dependent variable is the change in real wages for a individual between two consecutive years and the independent variable is the change in the TFP of the firm in which the individual works. Notice that for switchers the interpretation of a positive or negative productivity change is different than for stayers. For the latter group, it represents a productivity change for the firm in which they work, whereas for switchers it represents the difference in productivity between two different firms. Hence, a positive TFP change for a switcher indicates that the individual moved to a firm with higher TFP relative to the firm at which she used to work, and this change is independent of the actual change in productivity experienced by any of the firms. For instance, it is possible that the transition was motivated by a productivity decline in the firm of origin, or an increase in the productivity of the new firm that poached the worker, or both. To control for this effect we include in the regression three sources of TFP changes: the difference in TFP between the two firms (capturing the passthrough), the change in TFP experienced by the firm of origin (that is, the old firm), and the change in productivity of the destination firm (the new firm) relative to its TFP prior to the worker joining ${ }^{15}$. In particular, we modify the model in equation (1) as follows,

$$
\Delta w_{i j k t}=\alpha+\beta_{1}^{\eta} \eta_{j k t}+\beta_{2}^{\eta} \eta_{k k t}+\mathbb{Z}_{j t}^{\prime} \gamma+X_{i t}^{\prime} \lambda+\delta_{t}+\varepsilon_{i j k t}
$$

where $\Delta w_{i j k t}$ is the change in real log hourly wages of an individual that works in firm $j$ and moved from firm $k . \eta_{j k t}$ is defined as the unexpected in period $t-1$ innovation to the firm TFP at which the worker is employed. Specifically, $\eta_{j k t} \equiv \omega_{j t}-\mathbb{E}\left[\omega_{k t} \mid \omega_{k t-1}\right] . \quad \eta_{k k t}$ is

\footnotetext{
${ }^{15}$ Notice that this distinction is irrelevant for stayers as the firm of origin and destination is the same firm.
} 
Table 5: Passthrough Regressions for Stayers vs. Switchers

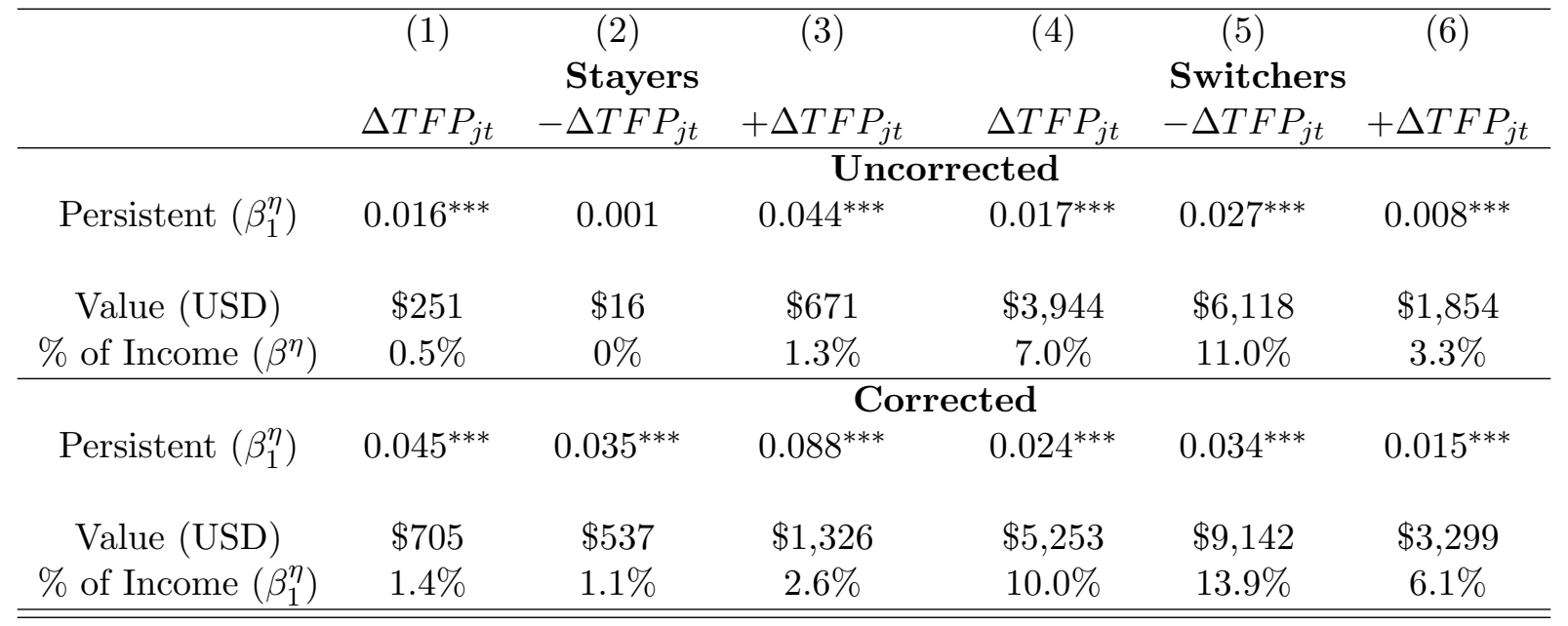

Note: Table 5 shows a set of panel regressions controlling for firm and worker characteristics. In columns 1-3, the dependent variable is the growth rate of real wages for individuals that stay in the same firm for two consecutive periods. In columns 4-6, the dependent variable is the growth rate of real wages for individuals that move between firms in consecutive periods. The main explanatory variable for stayers is the change in within-firm (log) TFP, while for switchers it is the difference in persistent $(\log )$ TFP between their old and new firm. The row named Value (USD) shows the change in real wages resulting from a one standard deviation shock to persistent TFP for a worker with the average wage for that group. The top panel shows estimates without correcting for selection while the bottom panel shows selection-corrected estimates. $* p<0.1, * * p<0.05, * * * p<0.01$. Robust standard errors are clustered at the firm level.

the unexpected in $t-1$ innovation to persistent productivity in the firm which the worker left. As before, the main coefficient of interest is $\beta_{1}^{\eta}$ which reflects the elasticity of a change in wages as a response to a shock in persistent TFP for the individual. While we do not present them here, we include as controls innovations to the transitory component of tfp for both the source and destination firms for each worker.

Table 5 shows the results. To facilitate the comparison between switchers and stayers we also show the results for stayers that were discussed in previous sections. The results in table 5 shows that the effect of TFP changes on wages of switchers is much stronger than it is for stayers, and this is true before and after the selection bias correction. Furthermore, the large difference in dollar values that is associated with the shock to persistent TFP is largely due to the differences in the standard deviation of TFP changes for stayers and switchers, as well as their difference in average wages. For example, the elasticity of wage growth to persistent TFP shocks is almost the same between stayers and switchers when they face negative shocks (0.035 vs 0.034$)$, but the average wage loss from a one standard deviation negative TFP shock is $\$ 537$ dollars for stayers vs $\$ 9,142$ dollars for switchers, or $1.1 \%$ of annual average income vs $13.9 \%$ annual average income. This stark difference between stayers and switchers is because that standard deviation of within-firm TFP changes for stayers is about 0.4 , but about 4 
for switchers - job switchers experience 10 times more variance in persistent TFP between years than job stayers. This makes sense since stayer TFP changes reflect the same firm's TFP growth, while TFP changes for switchers reflect the differences between the old and new firm, which can be significant. Furthermore, the average annual wage for stayers who see a negative TFP shock is $\$ 48,800$ dollars, while switchers the average is $\$ 65,800$ dollars. Therefore the same passthrough parameter is associated with drastically different wage losses for stayers and switchers. Lastly, similar to the stayer case we see an increase in the effect of TFP shocks on switchers' wage growth after correcting for selection bias. The result of this analysis suggests that we need to separately look at job stayers and job switchers when we think about TFP passthrough for workers, and the results need to be interpreted with extreme caution.

\subsection{Firm Side Heterogeneity}

Since passthrough may represent firm-level differences in wage setting or labor market power, it is natural to investigate how passthrough may differ across several dimensions of firm heterogeneity. Does passthrough differ for workers employed by firms in different sectors? Do more productive firms pass a larger or smaller fraction of their productivity gains to wages? To answer the first question we take the sample of stayers and run our passthrough analysis within a set of narrow industries. For the second question, we split the sample of firms into two groups. High productivity firms are those at the top quintile of the TFP level distribution whereas low productivity firms are those in the bottom quintile of the TFP level distribution. All the results in this section are corrected for selection.

The left panel of figure 6 shows the passthrough coefficient by industry sorted by the magnitude of the coefficient associated with a positive TFP change. The first thing to notice is the marked heterogeneity across sectors. For instance, the passthrough for the Transportation sector is almost ten times the passthrough estimated for Utilities. Second, Manufacturing sits close to the bottom of the distribution with a coefficient that is lower than the overall average. The right side of figure 6 shows the passthrough coefficient for a negative TFP change preserving the same order used for positive shocks. The differences across industries are again remarkable. It is clear also that industries that command high positive passtrough are not the same firms that generate high negative passthrough. Case in point is Arts, whose negative passthrough ranks amongst the highest.

Next, we study whether firms of different productivity levels pass shocks differently to 
Figure 6: Passthrough by Industry
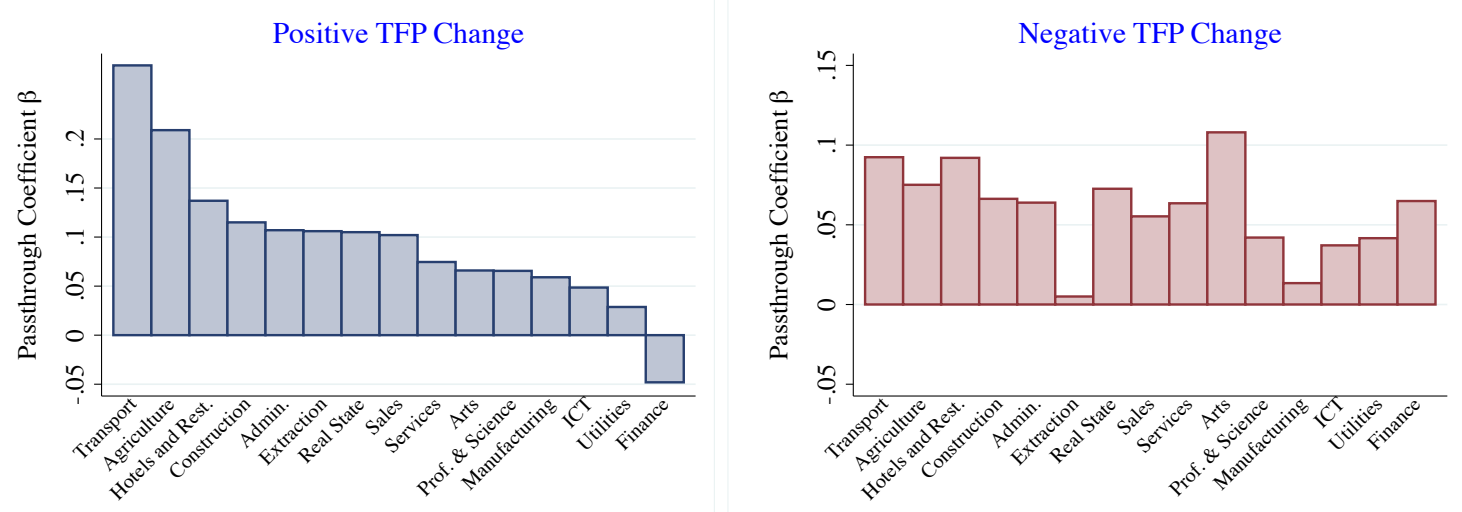

Note: The left panel of figure 6 shows the coefficient of the change in firm-level productivity on a OLS panel regression as in equation (1) conditional on the productivity change to be positive within aggregate industry groups. The right panel shows the results for negative productivity changes. All coefficients are statistically significant at the $1 \%$ level with robust standard errors clustered by firm.

their workers. For instance, it is possible that firms which experience a persistent decline in productivity cannot continue to operate without reducing the wages of their workers. In such cases, we should see a higher passthrough among lower productivity firms. Other the other hand, if low productivity firms are more vulnerable to productivity shocks due to financial constraints or other frictions, they may leave the market and therefore existing low TFP firms may have lower passthrough in the data. We look at high vs low TFP firms, as defined above, and run our set of panel regressions for each group, controlling for worker-side selection. ${ }^{16}$.

The results are shown in table 6. Comparing columns (1) and (4), one can see that the average passthrough among high TFP firms is significantly larger than passthrough among low TFP firms. This difference is more stark in the passthrough for negative TFP changes. In fact, the passthrough coefficient of negative shocks is positive and significant for workers in high TFP firms, whereas for workers in low TFP firms, the passthrough is though significant but very small in magnitude. The passthrough of positive shocks is also significantly larger among high TFP firms, though generally smaller than the negative passthrough coefficient. Taken together, these result suggest that low productivity firms provide better insurance to

\footnotetext{
${ }^{16}$ Our results can also be affected by the selection of firms into or out of the sample. As discussed in the main text, if firms of low TFP are more likely to leave the sample and exit the market, then, the passthrough of negative TFP shocks to wages might be underestimated. Ideally we could use firm borrowing constraints as an instrument in the selection correction procedure, but we do not currently have that data so firm selection is a potential issue in our analysis
} 
Table 6: Passthrough regression for high and low TFP firms

\begin{tabular}{ccccccc}
\hline & $(1)$ & $(2)$ & $(3)$ & $(4)$ & $(5)$ & $(6)$ \\
& \multicolumn{2}{c}{ High TFP Firms } & \multicolumn{3}{c}{ Low TFP Firms } \\
& $\Delta T F P_{j t}$ & $-\Delta T F P_{j t}$ & $+\Delta T F P_{j t}$ & $\Delta T F P_{j t}$ & $-\Delta T F P_{j t}$ & $+\Delta T F P_{j t}$ \\
\hline A & & & \multicolumn{2}{c}{ All Workers } \\
Persistent $\left(\beta^{\eta}\right)$ & $0.215^{* * *}$ & $0.219^{* * *}$ & $0.177^{* * *}$ & $0.025^{* * *}$ & $0.015^{* * *}$ & $0.075^{* * *}$ \\
& & & & & \\
Value (USD) & $\$ 3,088$ & $\$ 3,088$ & $\$ 2,602$ & $\$ 403$ & $\$ 235$ & $\$ 1,175$ \\
$\%$ of Income & $6.5 \%$ & $6.6 \%$ & $5.3 \%$ & $0.8 \%$ & $0.5 \%$ & $2.3 \%$ \\
\hline B & & & High Wage Workers & \\
Persistent $\left(\beta^{\eta}\right)$ & $0.413^{* * *}$ & $0.401^{* * *}$ & $0.240^{* * *}$ & $0.075^{* * *}$ & $0.074^{* * *}$ & $0.138^{* * *}$ \\
Value (USD) & $\$ 10,339$ & $\$ 9,483$ & $\$ 6,495$ & $\$ 1,846$ & $\$ 1,829$ & $\$ 3,374$ \\
$\%$ of Income & $12.4 \%$ & $12.0 \%$ & $7.2 \%$ & $2.3 \%$ & $2.2 \%$ & $4.1 \%$ \\
\hline C & & & Low Wage Workers & \\
Persistent $\left(\beta^{\eta}\right)$ & $0.106^{* * *}$ & $0.097^{* * *}$ & $0.221^{* * *}$ & $0.050^{* * *}$ & $0.034^{* * *}$ & $0.079^{* * *}$ \\
Value (USD) & $\$ 906$ & $\$ 822$ & $\$ 1,947$ & $\$ 470$ & $\$ 319$ & $\$ 738$ \\
$\%$ of Income & $3.2 \%$ & $2.9 \%$ & $6.6 \%$ & $1.5 \%$ & $1.0 \%$ & $2.4 \%$ \\
\hline \hline
\end{tabular}

Note: Table 6 shows a set of panel regressions controlling for firm and worker characteristics. In each column, the dependent variable is the growth rate of real wages for individuals that stay in the same firm for two consecutive periods. The main explanatory variables are estimated shocks to the transitory and persistent components of firm-level (log) TFP. The row named Value (USD) shows the change in real (USD) wages resulting from a one standard deviation shock to TFP for a worker with the average wage for that group. Columns 1-3 show results for firms in the top 20 percentile of the TFP distribution, while columns $4-6$ show results for firms in bottom 20 percentile of the TFP distribution. All panels show estimates correcting for worker-side selection but not firm-side selection. $* p<0.1, * * p<0.05, * * * p<0.01$. Robust standard errors are clustered at the firm level.

workers in the face of negative shocks. This result is in contrast with the basic intuition that high TFP firms (which are typically larger and potentially have better access to the financial markets) should be more capable to respond to shocks without impacting labor earnings. This could be due to the firm selection issue that we raised earlier, or could be due to high TFP firms existing in industries with wage contracts tying wages to firm performance more than low productivity firms, similar with the analysis with the difference between high wage workers and low wage workers. In fact, dividing sample up further by high wage and low wage workers who work in high TFP and low TFP firms, we see that high wage workers who work at high wage firms are the most sensitive to persistent TFP shocks. 
Table 7: Passthrough Across the Business Cycle

\begin{tabular}{ccccccc}
\hline & $(1)$ & $(2)$ & $(3)$ & $(4)$ & $(5)$ & $(6)$ \\
& \multicolumn{2}{c}{ Recessions (08-09) } & \multicolumn{2}{c}{ Expansions (05-06) } \\
& $\Delta T F P_{j t}$ & $-\Delta T F P_{j t}$ & $+\Delta T F P_{j t}$ & $\Delta T F P_{j t}$ & $-\Delta T F P_{j t}$ & $+\Delta T F P_{j t}$ \\
\hline A & & \multicolumn{5}{c}{ All Workers } \\
Persistent $\left(\beta^{\eta}\right)$ & $0.083^{* * *}$ & $0.082^{* * *}$ & $0.122^{* * *}$ & $0.036^{* * *}$ & $0.029^{* * *}$ & $0.058^{* * *}$ \\
& & & & & \\
Value (USD) & $\$ 1,326$ & $\$ 1,342$ & $\$ 1,879$ & $\$ 570$ & $\$ 453$ & $\$ 890$ \\
$\%$ of Income & $2.5 \%$ & $2.5 \%$ & $3.6 \%$ & $1.0 \%$ & $0.9 \%$ & $1.7 \%$ \\
\hline B & & \multicolumn{5}{c}{ High Wage Workers } \\
Persistent $\left(\beta^{\eta}\right)$ & $0.181^{* * *}$ & $0.205^{* * *}$ & $0.234^{* * *}$ & $0.091^{* * *}$ & $0.091^{* * *}$ & $0.098^{* * *}$ \\
Value (USD) & $\$ 4,565$ & $\$ 5,186$ & $\$ 5,790$ & $\$ 2,249$ & $\$ 2,250$ & $\$ 2,433$ \\
$\%$ of Income & $5.4 \%$ & $6.2 \%$ & $7.0 \%$ & $2.7 \%$ & $2.7 \%$ & $2.9 \%$ \\
\hline C & & \multicolumn{5}{c}{ Low Wage Workers } \\
Persistent $\left(\beta^{\eta}\right)$ & $0.076^{* * *}$ & $0.052^{* * *}$ & $0.101^{* * *}$ & $0.053^{* * *}$ & $0.044^{* * *}$ & $0.069^{* * *}$ \\
Value (USD) & $\$ 738$ & $\$ 503$ & $\$ 956$ & $\$ 503$ & $\$ 436$ & $\$ 655$ \\
$\%$ of Income & $2.3 \%$ & $1.6 \%$ & $3.0 \%$ & $1.6 \%$ & $1.3 \%$ & $2.1 \%$ \\
\hline \hline
\end{tabular}

\begin{abstract}
Note: Table 7 shows a set of panel regressions controlling for firm and worker characteristics. In each column, the dependent variable is the growth rate of real wages for individuals that stay in the same firm for two consecutive periods. The main explanatory variable is the change in within-firm (log) TFP. The row named $\$$ Value shows the change in real (USD) wages resulting from a one standard deviation shock to TFP for a worker with the average wage for that group. Columns 1-3 show results for years 2008 and 2009, while columns 4-6 show results 2005 and 2006 . The top panel shows estimates without correcting for selection while the bottom panel shows selection-corrected estimates. $* p<0.1, * * p<0.05, * * * p<0.01$. Robust standard errors, below the point estimates, are clustered at the firm level.
\end{abstract}

\title{
5.5 Expansion Periods vs. Recession Periods
}

Like the rest of the world Denmark was hit by a severe economic downturn in 2008. The decline in Danish GDP was under-way at the beginning of 2008 accompanied by a large drop in labor market hiring and an increase in separation rates. Arguably, workers in recessions and expansions face different labor market environments and therefore the passthrough effects from firm-level idiosyncratic shocks to wages may also be different. To investigate if this is the case, we estimate our passthrough regression separately in recession years (2008 to 2009) and expansion years (2005 to 2006). The results are presented in Table 7.

The left three columns are the results for Recessions, and the right three columns show the results for Expansions. All panels show the results of estimating passthrough while correcting for selection bias. The difference between recessions and expansions is clear: in recessions, on average, workers experience significant passthrough when firms experience 
negative TFP shocks, while in expansions workers are relatively insured against downside risk - the passthrough for negative TFP shock is significant but small especially for workers between the 20th and 80th wage percentiles.

The results in panel A show the average passthrough effect in expansions vs recessions for all workers. As discussed in the previous subsections, workers with different average wages may be affected differently by TFP shocks. This may be especially true along the business cycle, since potentially low wage workers are more or less sensitive to recessions than high wage workers. The results shown in panels $\mathrm{B}$ and $\mathrm{C}$ confirm this difference between wage groups. Low wage workers don't have much variation compared to high wage workers in terms of passthrough elasticity, but do see a stronger passthrough effect in recessions compare to expansions. High workers are much more sensitive to recessions. In the recession, high wage worker negative shock passthrough is 10 percentage points higher than in the expansion. The difference in the average dollar value is also significant. This is intuitive - firms may be more likely to adjust wages for workers who are paid highly. At the bottom, especially when wages are close to the minimum wage, there isn't much room where firms can adjust wages, so firms are more likely to adjust among other dimensions such as employment or working hours. Generally speaking, low wage workers in expansions are least sensitive to TFP shocks while high wage workers in recessions are the most sensitive. This suggests that low wage workers get much more insurance from the firm when their firms are hit by TFP shocks. High wage workers on the other hand do not have nearly as much insurance in terms of wage risk, so their wages will vary much more due to TFP shocks, especially when the economy is in a downturn.

\section{Robustness}

\subsection{Long Term Effects of Shocks}

One key question we address is the degree to which the passthrough we have documented so far in our analysis represents transitory or permanent shocks to wages. This is important as changes in productivity that translate to permanent changes in worker wages represent a source of risk that is more difficult to insure against. To look at this we run regressions of the form

$$
\Delta \log w_{i j t}=\alpha+\beta^{\eta} \eta_{j, t}+\mathbb{Z}_{j t}^{\prime} \gamma+X_{i t}^{\prime} \lambda+\delta_{t}+\varepsilon_{i j t}
$$


where, unlike our basic specification in equation 1, the dependent variable is defined as $\Delta \log w_{i j t}=\log w_{i j t+3}-\log w_{i j t-1}$. Here, the coefficient $\beta^{\eta}$ captures the long lasting effect on wages of a change in the persistent shock to firm's productivity, $\eta$. Thus we are looking at the effect of a shock in TFP in period $t$ on the total change in wages from $t-1$ to $t+3$. We also control for a large set of worker characteristics (age, gender, tenure in the firm, lag hourly wages, etc.) and firm characteristics (firm size, age, and lag productivity).

Table 8 shows the results for several dimensions of heterogeneity. First it's clear that productivity shocks at the firm level have a long lasting impact on workers wages and this effect greatly differs across groups. For instance, a high wage worker of a firm that experiences a positive change in productivity of one standard deviation between periods $t-1$ and $t$ will have gained by period $t+3 \$ 5,800$ USD more than an similar worker at an otherwise identical firm with no TFP shock. The effect for low wage workers is milder but still significant as a change of one standard deviation in productivity generates a $1 \%$ increase in their wages after a year. Negative productivity shocks at the firm level also have long lasting effect on wokers wages, specially for high wage workers and young workers. ${ }^{17}$

\subsection{Other TFP and Wage Measures}

Many paper have investigated the passthrough from firm shocks to worker wages. A detailed discussion of how our paper relates to other papers in the literature can be found in section ??. In this section we present the same analysis as in our baseline results, but with an alternative firm TFP estimator and annual wages instead of hourly wages as a robustness check. The measures that we use in this section are standard in the literature so it is easier for us to compare our results the literature. The details of the TFP estimation that we use in this section can be found in appendix B, though generally we assume firms use a Cobb Douglas technology to produce output, which we estimate using the standard approach from Levinsohn and Petrin (2003). We also use value added as an indicator of firm productivity which is fairly standard in the passthrough literature. Another major difference between this section and our main estimation is the wage measure. In the rest of the paper, we use an annualized or hourly wage which corrects for individual changes in hours or days worked. In this section we use the annual earnings from a job which does not correct for changes in days

\footnotetext{
${ }^{17}$ Our results also suggest a significant role for transitory shocks - the $\epsilon_{j, t}$ in the firm's productivity process - on long term changes of worker wages although the effects are smallers relative to the persistent shock but still significant. In fact, shocks to the transitory component of productivity have an impact on wages that is half as much as the impact of the persistent component.
} 
Table 8: Long Term Passthrough

\begin{tabular}{|c|c|c|c|c|c|c|}
\hline \multirow{3}{*}{$\mathrm{A}$} & (1) & $(2)$ & (3) & (4) & (5) & (6) \\
\hline & & Stayers & & \multicolumn{3}{|c|}{ Expansion } \\
\hline & $\Delta T F P_{j t}$ & $-\Delta T F P_{j t}$ & $+\Delta T F P_{j t}$ & $\Delta T F P_{j t}$ & $-\Delta T F P_{j t}$ & $+\Delta T F P_{j t}$ \\
\hline Persistent $\left(\beta^{\eta}\right)$ & $0.027^{* * *}$ & $0.024^{* * *}$ & $0.046^{* * *}$ & $0.037^{* * *}$ & $0.018^{* * *}$ & $0.082^{* * *}$ \\
\hline Value (USD) & 419 & 369 & 688 & 570 & 285 & 1,258 \\
\hline$\%$ of Income & $1 \%$ & $1 \%$ & $1 \%$ & $1 \%$ & $0 \%$ & $2 \%$ \\
\hline B & \multicolumn{3}{|c|}{ High Wage } & \multicolumn{3}{|c|}{ Low Wage } \\
\hline Persistent $\left(\beta^{\eta}\right)$ & $0.238^{* * *}$ & $0.239^{* * *}$ & $0.246^{* * *}$ & $0.046^{* * *}$ & $0.030^{* * *}$ & $0.051^{* * *}$ \\
\hline Value (USD) & 5,874 & 5,874 & 6,009 & 419 & 285 & 453 \\
\hline$\%$ of Income & $7 \%$ & $7 \%$ & $7 \%$ & $1 \%$ & $1 \%$ & $1 \%$ \\
\hline $\mathrm{C}$ & \multicolumn{3}{|c|}{ Young } & \multicolumn{3}{|c|}{ Old } \\
\hline Persistent $\left(\beta^{\eta}\right)$ & $0.113^{* * *}$ & $0.101^{* * *}$ & $0.144^{* * *}$ & $0.031^{* * *}$ & $0.039^{* * *}$ & $0.021^{* * *}$ \\
\hline Value (USD) & 1,544 & 1,409 & 1,896 & 503 & 637 & 335 \\
\hline$\%$ of Income & $3 \%$ & $3 \%$ & $4 \%$ & $1 \%$ & $1 \%$ & $1 \%$ \\
\hline
\end{tabular}

Note: Table 8 shows a set of panel regressions controlling for firm and worker characteristics. In each column, the dependent variable is the growth rate of real wages between period $t-1$ and period $t+3$. The main explanatory variable is the persistent component in the firm's productivity process. The row labeled Value (USD) shows the change in real wages resulting from a one standard deviation shock to TFP for a worker with the average wage for that group. The definitions of stayer/switcher, high/low wage and expansion/recession are as in previous tables. $* p<0.1, * * p<0.05, * * * p<0.01$. Robust standard errors are clustered at the firm level.

or hours worked. The details of our wage cleaning procedure, and how our wage and TFP measure compare to standard measures can be found in section 3.2. Table 9 presents our baseline result without selection using the alternative TFP and wage measures. Similar to our baseline tables, column (1) shows the passthrough from (total) TFP growth on average, while column (2) and column (3) shows the passthrough for positive and negative shocks separately. A glance at the results shows that the passthrough from firm TFP changes to worker wage growth is positive and statistically significant. In column (2) we see that the coefficient on negative TFP is close to zero and is not statistically significant, suggesting that firms insulate workers from negative productivity shocks. Column (3) however, shows a strong and positive correlation between TFP changes and wage growth within the group of firms observing positive TFP growth, indicating that firms pass a large fraction of positive changes in productivity to wages. In column (4), we show that using value added as an index for firm productivity also provides positive passthrough. The positive but small relationship between changes in TFP and wage growth that we find using annual wages and standard 
TFP measures (using labor hours as the labor input) falls in line with results found in other papers (see for instance Juhn et al. (2018) and Rute Cardoso and Portela (2009)). These results are based on the sample of workers that stay in the same firm for two consecutive periods. However, as above, these regression results are likely biased by selection. We then implement the same correction strategy as we have in the baseline model with the results shown in table 10 .

Similar with the results we present in the baseline model, the selection-corrected results here are remarkably different from the non-corrected estimates. The coefficient for average passthrough almost doubles in magnitude. The effect of a negative (totaly) productivity change goes from being near zero in the top panel to 0.087 in the bottom panel, which again mirrors are main results above. This implies that a worker in a firm receiving a negative productivity shock of one standard deviation sees his annual income reduced by $\$ 2,403$, a value that is almost ten times larger relative to the value observed when one does not control for selection. We also find a significant increase in the effect of a positive productivity shock into wages as it is shown in column (3).

Table 9: Baseline Passthrough Regressions

\begin{tabular}{ccccc}
\hline & $(1)$ & $(2)$ & $(3)$ & $(4)$ \\
& $\Delta T F P_{j t}$ & $-\Delta T F P_{j t}$ & $+\Delta T F P_{j t}$ & $\Delta V A_{j t}$ \\
\hline$\beta$ & $\begin{array}{c}0.075^{* * *} \\
(0.003)\end{array}$ & $\begin{array}{c}0.011 \\
(0.007)\end{array}$ & $\begin{array}{c}0.113^{* * *} \\
(0.005)\end{array}$ & $\begin{array}{c}0.111^{* * *} \\
(0.005)\end{array}$ \\
\hline & & & & \\
\hline Value (USD) & $\$ 2,090$ & $\$ 294$ & $\$ 3,167$ & \\
\hline \hline
\end{tabular}

Note: Table 9 shows a set of panel regressions controlling for firm and worker characteristics. In each column, the dependent variable is the growth rate of real wages for individuals that stay in the same firm for two consecutive periods. From columns (1) to (3) the main explanatory variable is the change in firm-level (log) TFP. In column (4) the main explanatory variable is the change in the firm-level (log) value added. The row named Value (USD) shows the change in real wages resulting from a one standard deviation shock to TFP for a worker with the average wage for that group. $* p<0.1, * * p<0.05, * * * p<0.01$. Robust standard errors, below the point estimates, are clustered at the firm level.

In each of the cases, the results using alternative TFP and wage measures that we present in this section are similar to our baseline result qualitatively, and are in line with the literature before correcting for selection bias. However the selection-corrected passthrough effect is much stronger when using the alternative TFP and wage measures than using our baseline TFP and wage measures. This is for two reasons. First, without cleaning the annual wage data, one may conflate the wage effect of passthrough with the extensive effect on hours or days worked. When we see worker annual wages decrease, it is entirely possible that the wage 
Table 10: Passthrough Regressions Controlling for Selection

\begin{tabular}{|c|c|c|c|}
\hline & $\begin{array}{c}(1) \\
\Delta T F P_{j t}\end{array}$ & $\begin{array}{c}(2) \\
-\Delta T F P_{j t}\end{array}$ & $\begin{array}{c}(3) \\
+\Delta T F P_{j t}\end{array}$ \\
\hline & \multicolumn{3}{|c|}{ Uncorrected } \\
\hline$\beta$ & $\begin{array}{c}0.075^{* * *} \\
(0.003)\end{array}$ & $\begin{array}{c}0.011 \\
(0.007)\end{array}$ & $\begin{array}{c}0.111^{* * *} \\
(0.004)\end{array}$ \\
\hline Value (USD) & $\$ 2,090$ & $\$ 294$ & $\$ 3,617$ \\
\hline$\beta$ & $\begin{array}{c}0.137^{* * *} \\
(0.003)\end{array}$ & $\begin{array}{c}\text { Correctec } \\
0.087^{* * *} \\
(0.007)\end{array}$ & $\begin{array}{c}0.164^{* * *} \\
(0.004)\end{array}$ \\
\hline Value (USD) & $\$ 3,813$ & $\$ 2,403$ & $\$ 4,569$ \\
\hline
\end{tabular}

Note: Table 10 shows a set of panel regressions controlling for firm and worker characteristics. In each column, the dependent variable is the growth rate of real wages for individuals that stay in the same firm for two consecutive periods. The main explanatory variable is the change in firm-level $(\log )$ TFP. The row named $\$$ Value shows the change in real (USD) wages resulting from a one standard deviation shock to TFP for a worker with the average wage for that group. The top panel shows estimates without correcting for selection while the bottom panel shows selection-corrected estimates. $* p<0.1, * * p<0.05, * * * p<0.01$. Robust standard errors, below the point estimates, are clustered at the firm level.

level has not adjusted at all but the individual has reduced their working time and thus their annual earnings. Therefore the passthrough effect will be overestimated using the annual wage measure. Second, when estimating TFP using employee counts or hours worked as the labor input without taking into effect differences in quality and effective working hours, one could attribute variation in revenue entirely to TFP rather than variation in input quality, and therefore measure the passthrough from TFP changes to wages incorrectly. Estimates of TFP which do not control for labor quality also tend to have much higher measured variance in TFP shocks than labor-quality adjusted estimates of $\mathrm{TFP}^{18}$. To sum up, ignoring selection will largely underestimate the passthrough from firm shocks to wages, but using less accurate measures of TFP and wages will tend to over-estimate the passthrough effect.

\section{Quantitative Analysis}

Our previous analysis establishes the key relations between the shocks affecting the firms and the passthrough of these shocks to workers earnings. Given these relationships, it is important to imbue the rich heterogeneity found in the data into a tractable stochastic

\footnotetext{
${ }^{18}$ See Fox and Smeets (2011).
} 
income process which can be incorporated into an economic model. Doing so is relevant for at least two reasons. First, will allow us to evaluate the social value of the insurance provided by the firms and also to estimate how much workers would be willing to pay in order to increase the degree of insurance they receive. Second, given the large differences in passthrough observed in the data across workers and firms with different characteristics, using a model will allow us to better evaluate the welfare costs of this heterogeneity, the cost of idiosyncratic income fluctuations, and the welfare cost of firm-level shocks.

In order to make progress on these issues, we first estimate a stochastic income process that incorporates both firms' and workers' characteristics. In particular, we extend the standard stochastic income process adopted in the literature by incorporating firm-level shocks that are passed to workers in different degrees. Importantly, we jointly use workerand firm-level data. Most papers which estimate income processes use only data on individual characteristics, wages, and transitions across different employment statuses (see for instance Low et al. (2010) and Guvenen (2007)). To the best of our knowledge, this is one of the first papers to directly use firm-level shocks and passthrough to wages in the estimation of a stochastic income process allowing for an asymmetric and heterogeneous response of wages to firm shocks.

We then incorporate the estimated income process in an otherwise standard incomplete markets life-cycle consumption-savings model. Using this model we study the welfare value of the (partial) insurance provided by the firms. We do this by means of three counterfactual exercises. In the first, we completely eliminate the insurance provided by the firms (i.e. we allow the passthrough from firm shocks to wages to be equal to one) and we ask what are the welfare losses relative to the baseline, partial insurance, case. In the second, we compare the baseline economy with a case in which the passthrough is zero (i.e. full insurance) and ask how much, in terms of consumption, workers are willing to pay in order to eliminate their exposure to firm-level shocks. Finally we investigate the importance of the heterogeneity in passthrough that we unveil to the welfare impact of uninsurable income risk. We do this by comparing our baseline economy to one in which the passthrough for all workers and firms is set to the average observed in the economy.

In the following sections we set up the basic properties of the stochastic income process and the life cycle income model that we will use in our welfare evaluation. 


\subsection{Wages and Shocks}

We assume that the real wage of an individual $i$ working in firm $j$ in period $t, w_{i, j, t}$ is given by,

$$
\log w_{i, j, t}=\mu_{t}+x_{i, j, t} \Gamma+\tilde{\eta}_{i, t}+\tilde{\varepsilon}_{i, t}+\psi_{i, j, t}\left(z_{j(i), t}, z_{j(i), t-1}\right)
$$

where $\mu_{t}$ represents the average level of real wages in the economy, $x_{i, j, t}$ is a vector of regressors including worker and firm level characteristics, $\tilde{\eta}_{i, t}$ is the persistent component of wages that is uncorrelated to firm-level shocks, $\tilde{\varepsilon}_{i, t}$ is the transitory component of wages that is uncorrelated with the persistent component and with firm-level shocks, and $z_{j(i), t}$ is a measure of firm $j$ 's TFP which affects all the workers of firm $j$ in period $t$. Here the subscript $j(i), t$ denotes the firm at which individual $i$ works in period $t$. The heterogeneity in passthrough is captured by the function $\psi_{i, j, t}$ which may depend on worker and firm-level characteristics. ${ }^{19}$. The function $\psi_{i, j, t}$ is flexible in that it allows for asymmetric responses to increases or decreases in TFP, as well as detailed heterogeneity in the degree of passthrough and the possibility that the worker switches firms between periods $t-1$ and $t$. As mentioned in section 3.3, firm TFP can be further expressed as $z_{j, t}=g\left(\omega_{j, t-1}\right)+\eta_{j, t}+\varepsilon_{j, t}$, where $g\left(\omega_{j, t-1}\right)$ is the anticipated value of productivity, $\eta_{j, t}$ is the unanticipated permanent shock to productivity and $\varepsilon_{j, t}$ is the unanticipated transitory shock.

\section{Estimation Procedure}

We start by estimating firms' productivity process. To keep the model as tractable as possible, we assume the TFP follows an AR1 process,

$$
z_{j, t}=c_{j}+\rho_{j}^{z} z_{j, t-1}+\xi_{j, t}
$$

To obtain the first-order-autocorrelation parameter we demean our estimates of firm-level productivity so $c_{j}=0$, and we run the above regression in the data, which gives us a value of $\rho^{z}$ of 0.97 . This value is relatively more persistent than the one used in most of the literature mostly because our TFP estimation carefully controls for observables in a nonparametric fashion as oppose to attributing much of the variation in firm revenues to variation in TFP. We discuss in more detail about our TFP estimation strategy and

\footnotetext{
${ }^{19}$ Notice in this formulation that firm TFP and passthrough parameters enter as an exogenous process. Modeling the endogenous formation of passthrough and decisions of firms in response to exogenous productivity shocks, although beyond the scope of this paper, is an important area of our ongoing research agenda.
} 
the corresponding properties in section $3.3 .^{20}$. We assume $\xi_{j t}$ is iid and follows a mean zero normal mixture distribution: with probability $p, \xi_{j, t} \sim \mathbb{N}\left(\mu_{1}, \sigma_{1}\right)$, and with probability $(1-p)$, $\xi_{j, t} \sim \mathbb{N}\left(\mu_{2}, \sigma_{2}\right)$, where $\mu_{2}=-\frac{p}{1-p} \mu 1$. We then estimate the remaining four parameters $\left\{p, \mu_{1}, \sigma_{1}, \sigma_{2}\right\}$ following the method developed by Civale et al. (2016). The estimation results are shown in Table 11. Note that the moments (mean, variance, skewness, kurtosis) that we use for our estimation in the TFP process are from the worker-weighted TFP distribution. This simplifies the firm-to-worker match since in the current version of our model we do not have multi-worker firms. Each firm only employs one worker and therefore we match our model to the worker-weighted TFP distribution.

Given our estimated process for firm productivity, we then estimate the worker wage process. In our baseline setting, we assume that firms and workers are randomly matched. Specifically we first draw firms based on the workers weighted distribution (estimated in the previous step). We then draw one worker for each firm, so workers and firms matching is independent. This assumption allows us to estimate firm side parameters and workers side parameters separately, which greatly simplified the estimation ${ }^{21}$. One of our key innovation is that in our stochastic wage process, we capture wage changes that comes from firms passing TFP shocks to the workers heterogeneously across different worker and firm groups, and non-symmetrically between positive and negative shocks. We assume that the passthrough function, $\psi_{i, j, t}\left(z_{j(i), t}, z_{j(i), t-1}\right)$, is linear and we ignore the time effect and observable effects for now ${ }^{22}$. The simplified wage process is then:

$$
\log y_{i, j, t}=\eta_{i, t}+\varepsilon_{i, t}+\psi_{0 i, j, s} z_{j, t-1}+\psi_{1 i, j, s}\left(z_{j, t}-z_{j, t-1}\right) \mathbf{1}_{\Delta z_{j, t}>0}+\psi_{2 i, j, s}\left(z_{j, t}-z_{j, t-1}\right) \mathbf{1}_{\Delta z_{j, t} \leq 0}
$$

where $\eta_{i, t}$ is the permanent component of workers wages which follows a standard $\operatorname{AR}(1)$ process: $\eta_{i, t}=c_{i}+\rho_{i}^{\eta} \eta_{i, t-1}+\zeta_{i, t}$, and $\varepsilon_{i, t}$ is the transitory component. We assume that $\zeta(i, t) \sim \mathbb{N}\left(0, \sigma_{\zeta}\right)$ and $\varepsilon_{i, t} \sim \mathbb{N}\left(0, \sigma_{\epsilon}\right)$, so we have now seven parameters to estimate:

$$
\omega=\left\{\sigma_{i}^{\varepsilon}, \sigma_{i}^{\zeta}, c_{i}, \rho_{i}^{\eta}, \psi_{0}, \psi_{1}, \psi_{2}\right\}
$$

\footnotetext{
${ }^{20}$ Further investigation and discussion on how the TFP measure in this paper compare to the TFP measures in existing literature in terms of properties can be found in Chan et al. (2019)

${ }^{21}$ Alternatively, one could draw firms and workers jointly according to the joint distribution that we observe in the data. This will then require the joint estimation of all firms side parameters and workers side parameters as well as the covariance parameters.

${ }^{22}$ Time effect and workers observable characteristics are added in the full model section, and the estimation of the full model is ongoing work.
} 
The wage process specified in equation 12 implies the following moments,

$$
\begin{aligned}
\Delta \log y_{i j t}= & \Delta \eta_{i, t}+\Delta \varepsilon_{i t}+\left(\psi_{1} \mathbf{1}_{\Delta z_{j, t}>0}+\psi_{2} \mathbf{1}_{\Delta z_{j, t} \leq 0}\right) \Delta z_{j, t} \\
& +\left(\psi_{0}-\psi_{1} \mathbf{1}_{\Delta z_{j, t-1}>0}-\psi_{2} \mathbf{1}_{\Delta z_{j, t-1} \leq 0}\right) \Delta z_{j, t-1} \\
\mathbb{E}\left(\log y_{i j t}\right)= & \frac{c_{i}}{1-\rho_{i}^{\eta}}+F_{1}\left(\psi_{0}, \psi_{1}, \psi_{2}, \text { firmparams }\right) \\
S d\left(\log y_{i j t}\right)= & \sigma_{i}^{\varepsilon}+\frac{\sigma_{i}^{\zeta}}{\sqrt{1-\rho_{i}^{\eta 2}}}+F_{2}\left(\psi_{0}, \psi_{1}, \psi_{2}, \text { firmparams }\right) \\
\mathbb{E}\left(\log y_{i j t} \log y_{i j t-1}\right)= & \frac{c_{i}^{2}}{1-\rho_{\eta}}+\rho_{\eta} \frac{\sigma_{\zeta}^{2}}{1-\rho_{\eta}^{2}}+F_{3}\left(\psi_{0}, \psi_{1}, \psi_{2}, \text { firmparams }\right) \\
S d\left(\Delta \log y_{i j t, t-1}\right)= & \sqrt{2} \sigma_{i}^{\varepsilon}+\sqrt{\frac{2}{1+\rho}} \sigma_{i}^{\zeta}+F_{4}\left(\psi_{0}, \psi_{1}, \psi_{2}, \text { firmparams }\right) \\
S d\left(\Delta \log y_{i j t, t-3}\right)= & \sqrt{2} \sigma_{i}^{\varepsilon}+\sqrt{\frac{2}{1+\rho}}\left(1+\rho+\rho^{2}\right) \sigma_{i}^{\zeta}+F_{5}\left(\psi_{0}, \psi_{1}, \psi_{2}, \text { firmparams }\right)
\end{aligned}
$$

$F_{1}-F_{5}$ are functions of $\psi_{0}, \psi_{1}, \psi_{2}$, firm parameters, and TFP values which are predetermined in the firm side estimation. Given the asymmetric passthrough structure of our wage process, it is rather difficult to derive an analysis solution for our parameters. Hence, we instead use a mixure of simulated method of moments (SMM) and indirect inference to jointly estimate all seven parameters. Note that the mean and variance of log wage, the variance of the change of log wages at one and three years, and the one-period autocorrelation of wages gives us information about the first four parameters. To identify the three passthrough parameters, consider the auxiliary models:

$$
\begin{aligned}
\log y_{i j t} & =\bar{\beta}+\beta_{0} z_{j, t-1}+\epsilon_{1} \\
\Delta \log y_{i j t} & =\bar{\gamma}+\gamma_{1} \Delta z_{j, t} \mathbf{1}_{\Delta z_{j, t}>0}+\gamma_{2} \Delta z_{j, t} \mathbf{1}_{\Delta z_{j, t} \leq 0}+\epsilon_{2} .
\end{aligned}
$$

The goal is to bring the data and simulated data as close as possible through the lens of auxiliary model. That is, given a set of parameter guesses, we run the regression of the auxiliary model using the data (which gives us $\hat{\beta}_{0}, \hat{\gamma}_{1}$ and $\hat{\gamma}_{2}$ ) and using the simulated data generated from our economic model (which gives us $\tilde{\beta}_{0}, \tilde{\gamma}_{1}$ and $\left.\tilde{\gamma}_{2}\right)$. We want to bring $\left(\hat{\beta}_{0}, \hat{\gamma}_{1}\right.$, $\left.\hat{\gamma}_{2}\right)$ and $\left(\tilde{\beta}_{0}, \tilde{\gamma}_{1}, \tilde{\gamma}_{2}\right)$ as close as possible. Matching this auxiliary model's moments will give us information about $\psi_{0}, \psi_{1}$ and $\psi_{2}$. All together we have seven parameters to be identified, and we are matching the following eight moments to identify the parameters of the wage 
Table 11: TFP and Wage Parameter Estimation

\section{$\underline{\text { TFP Parameters }}$}

\begin{tabular}{|c|c|c|}
\hline Variable & Value & Description \\
\hline$\rho$ & 0.9702 & $\mathrm{AR}(1)$ parameter \\
\hline $\mathrm{p}$ & 0.9676 & Probability of the normal mixture of innovation in TFP \\
\hline$\mu_{1}$ & 0.1409 & mean of the first normal distribution in innovation \\
\hline$\sigma_{1}$ & 0.0017 & Standard deviation of the first normal distribution in innovation \\
\hline \multirow[t]{2}{*}{$\sigma_{2}$} & 0.7382 & Standard deviation of the second normal distribution in innovation \\
\hline & & Wage Process Parameters \\
\hline Variable & Value & Description \\
\hline$\rho_{\eta}$ & 0.701 & $\mathrm{AR}(1)$ parameter \\
\hline$\sigma_{\eta}$ & 0.1884 & Standard deviation of the permanent wage shock \\
\hline$\sigma_{\varepsilon}$ & 0.0537 & Standard deviation of the transitory wage shock \\
\hline$c_{\eta}$ & 3.8 & Average component in wage process \\
\hline$\psi_{0}$ & 0.0446 & TFP marginal effect on wage levels \\
\hline$\psi_{1}$ & 0.0126 & Positive TFP shock marginal effect on wage levels \\
\hline$\psi_{2}$ & 0.0036 & Negative TFP shock marginal effect on wage levels \\
\hline
\end{tabular}

process:

Moments $=\left\{\mathbb{E}\left(\log y_{i j t}\right), \mathbb{E}\left(\log y_{i j t} \log y_{i j t-1}\right), S d\left(\log y_{i j t}\right), S d\left(\Delta \log y_{i j t}\right), S d\left(\Delta \log y_{i j t, t-3}\right), \hat{\beta}_{0}, \hat{\gamma}_{1}, \hat{\gamma}_{2}\right\}$

This simple way of estimation will give us the estimation of the seven parameters for the wage process $\left(\omega_{1}-\omega_{7}\right)$.

\subsection{Estimation Results}

We further simplify the estimation considering that workers and firms are ex-ante homogeneous. This reduces the number of parameters to be estimated to twelve (five for firms and seven for workers). ${ }^{23}$ The estimation results are shown in Table 11, and Table 12 shows the model fit.

\footnotetext{
${ }^{23}$ Our current work extends our estimation method to account for fixed different across different firms and worker types.
} 
Table 12: Model Estimation Fit

$\underline{\text { TFP Moments }}$

\begin{tabular}{lccl} 
Variable & Data & Model & Description \\
\hline $\mathbb{E}(z)$ & 0 & 0.0001 & Mean of log TFP process parameter \\
$V(z)$ & 14.34 & 10.35 & Variance of log TFP process \\
$S(z)$ & -1.02 & -0.91 & Skewness of log TFP process \\
$K(z)$ & 3.32 & 3.89 & Kurtosis of log TFP process \\
\hline & & & $\underline{\text { Wage Moments }}$ \\
& & & \\
Variable & Data & Model & Description \\
\hline $\mathbb{E}(y)$ & 12.74 & 12.74 & Mean log wage (DKK) \\
$S d(y)$ & 0.15 & 0.07 & Standard deviation of log wage \\
$\mathbb{E}\left(y * y_{L}\right)$ & 162.28 & 162.27 & Autocorrelation of log wage \\
$S d(\Delta(y))$ & 0.03 & 0.05 & Standard deviation of changes in log wage \\
$S d\left(\Delta_{3}(y)\right)$ & 0.09 & 0.09 & Standard deviation of changes in 3 periods log wage \\
$\hat{\beta}_{0}$ & 0.04 & 0.04 & Auxiliary model coefficient \\
$\hat{\gamma}_{1}$ & 0.009 & 0.009 & Auxiliary model coefficient \\
$\hat{\gamma}_{2}$ & 0.009 & 0.009 & Auxiliary model coefficient \\
\hline \hline
\end{tabular}

\subsection{A Consumption-Savings Model}

In this section we study some key implications of the rich earnings dynamics implied by the stochastic process estimated in the previous section. We pose an heterogeneous agents incomplete markets life-cycle model in which workers are subject to the stochastic process described by equation 10. Individuals can borrow and save using a risk-free asset, $a_{i, t}$, with gross return $\left(1+r_{t}\right)$. Borrowing is limited by a predefined minimum level which in principle can depend on worker characteristics. Denote this minimum value as $\underline{a}_{i, t}$. We will also assume that the individuals pay taxes and receive benefits from the government, which will be modeled to match the Danish system. Finally, individuals value consumption $c_{i, t}$ by means of a time separable utility function, $u\left(c_{i, t}\right)$. The dynamic programming problem of an 
individual is given by,

$$
\begin{gathered}
V_{t}^{i}\left(a_{i, t}, w_{i, j, t}, \mu_{t}\right)=\max _{c_{i, t}, a_{i, t+1}}\left\{\frac{\left(c_{t}^{i}\right)^{1-\sigma}}{1-\sigma}+\beta \mathbb{E} V_{t}^{i}\left(a_{i, t+1}, w_{i, j, t+1}, \mu_{t+1}\right)\right\}, \\
\text { subject to } \\
c_{i, t}+a_{i, t+1}=a_{i, t}\left(1+r_{t}\right)+\left(1-\tau_{t}\left(w_{i, j, t}\right)\right) w_{i, j, t}+T_{t}\left(w_{i, j, t}\right), \\
\log w_{i, j, t}=\mu_{t}+\tilde{\eta}_{i, t}+\tilde{\varepsilon}_{i, t}+\psi_{i, j, t}\left(z_{j(i), t}, z_{j(i), t-1}\right), \\
\mu_{t+1}=\Gamma\left(\mu_{t}\right), a_{i, t+1} \geq \underline{a}
\end{gathered}
$$

where $\beta$ is the subjective discount factor, $\sigma$ governs risk aversion and the intertemporal elasticity of substitution, and $\mu_{t}$ is the distribution of individuals over idiosyncratic states. The tax function is defined by $\tau_{t}\left(w_{i, j, t}\right)$ while $T_{t}\left(w_{i, j, t}\right)$ is a government benefits function.

\section{Calibration}

To simplify the analysis, we assume that individuals are infinitely lived, and a period in our model corresponds to a year. The coefficient of risk aversion $\sigma$ is set to 2 as a conservative choice. The discount factor is chosen to match a wealth-to-income ratio of 4 , the returns to the risk free asset is set to $3 \%$, and the borrowing limit, $\underline{a}$ is set equal to the average annual earnigs in the economy.

The key element of our analysis is the stochastic income process faced by workers, and more importantly, the passthrough of firms' shocks to workers' wages. In our baseline analysis we consider the income process described by equation 12 and the parameters from table 11. We then consider two cases, the first sets $\psi_{1}=\psi_{2}=1$ which corresponds to a full symmetric passthrough of productivity shocks to wages. The second turns off the passthrough of positive shocks by setting $\psi_{1}=1$ but $\psi_{2}=1$.

\section{Model Fit}

Our model economy is able to generate substantial wealth inequality. Estimates from Jakobsen et al. (2017) show that in Denmark, $20 \%$ of total wealth is held by those at the top $1 \%$ of the wealth distribution, whereas $50 \%$ of total wealth is held by the topp $10 \%$. The bottom $50 \%$ of the distribution holds little to no wealth. In our model, the top $1 \%$ holds $15 \%$ of the wealth in the economy whereas the top $10 \%$ of households holds $45 \%$ of the total wealth. 
This is remarkable considering that standard consumption-savings models typically cannot account well for the large disparities in wealth observed in Denmark or other economies. ${ }^{24}$

Our first quantitative exercise allows answering the question: what is the value - in consumption equivalents - that workers assign to the insurance provided by the firms? In our simple setting, this implies comparing our benchmark economy to one in which firms' shocks are fully passed to workers $(\psi=\psi=1)$. Our estimates suggest that workers are willing to pay a very little amount of lifetime consumption for the insurance provided by firms (less than 1\%). This is because, in our model with infinitely lives workers with access to a risk-free asset, workers can undue the decrease of the insurance provided by the firms by increasing their life-time savings. The offsetting effect of an increase in capital accumulation reduces the steady-state value of the insurance provided by firms. At the same time, because there is an increase in the fraction of positive shocks that are passed to workers, the average workers wage increases. The value of the insurance for negative shocks, as expected, is more valuable for workers. We can evaluate that case by considering a 0 passthrough of positive shock, but a full passthrough from negative firms' shocks to workers wages. Adding a more realistic labor income process that takes into account employment status transition and a richer asset market, both of which are part of our ongoing work, will likely increase the insurance value provided by the firms.

\section{Conclusion}

In this paper, we offer new evidence on the effect of changes in firms' productivity on workers' wages. Using high quality, employer-employee matched administrative panel data we address two important issues the literature has ignored so far: the effect of selection and the impact of changes in firm-level productivity for workers that switch between firms. Moreover, we provide a more direct measure of firm' total factor productivity and we explore several degrees of heterogeneity among firms and workers types.

To control for selection, we use a novel approach that exploits employment and income information of spouses to estimate the probability that an individual stays in the same firm during a particular year. We find that controlling for selection has a major impact in the passthrough estimates from TFP shocks to wages. In fact, the OLS coefficient more than doubles when one has controlled for selection relative to the coefficient when selection

\footnotetext{
${ }^{24}$ For a survey see De Nardi (2015) and the references therein.
} 
issues are not addressed. In general, we find large and economically significant passthrough coefficients: After we have controlled for selection, we find that a worker in a firm that experiences a TFP change of one standard deviation sees her annual earnings increase by $\$ 1,500$ which is around $3 \%$ of the Danish income per capita. Considering that in any given year $33 \%$ of firms - which employ $40 \%$ of all the workers in Denmark - receive experience a persistent or transitory TFP shock of at least one standard deviation from the average, we see that the effect of firm-level shocks on wages is quite substantial. Furthermore, relative to continuing workers, the impact of TFP change for switchers is substantially larger.

Heterogeneity plays a major effect on shaping the effect of TFP shocks on wages. In fact, we find remarkable differences between workers at higher ranks of the income distribution - who are less insured against the positive and negative shocks affecting the firms - and workers at the bottom of the income distribution - for which the passthrough is lower and less economically significant. We also find extremely large differences across industries and for young and old workers.

In the second part of our paper, we estimate a rich stochastic income process that captures the salient features we observe in the data. Our major innovation is to consider an independent process of firm-level productivity as an additional shock affecting workers earnings directly and the estimation of a passthrough from the firm's shocks to workers wages using indirect inference. Our estimation suggests an important role for firm-level shocks in shaping the dynamics of workers' labor income. We then incorporate our estimated stochastic process into an otherwise standard consumption savings model. In our model, the insurance provided by the firms is of little value for the workers which can offset an increase in the passthrough from firm's shocks to wages - which increases income instability - by increasing asset accumulation. Incorporating a richer life-cycle into the model and a more realistic asset market will likely increase the importance of the insurance provided by firms, both of which are part of our ongoing work. 


\section{References}

Ackerberg, D. A., Caves, K. and Frazer, G. (2015). Identification properties of recent production function estimators. Econometrica, 83 (6), 2411-2451.

Bagger, J., Christensen, B. J. and Mortensen, D. T. (2014). Wage and labor productivity dispersion: The roles of total factor productivity, labor quality, capital intensity, and rent sharing. In 2014 Meeting Papers.

Barth, E., Bryson, A., Davis, J. C. and Freeman, R. (2016). It's where you work: Increases in the dispersion of earnings across establishments and individuals in the united states. Journal of Labor Economics, 34 (S2), S67-S97.

Chan, M., Salgado, S. and Xu, M. (2019). The distribution and evolution of firm productivity.

Civale, S., Díez-Catalán, L. and Fazilet, F. (2016). Discretizing a process with non-zero skewness and high kurtosis.

Comin, D., Groshen, E. L. and Rabin, B. (2009). Turbulent firms, turbulent wages? Journal of Monetary Economics, 56 (1), 109-133.

De NArdi, M. (2015). Quantitative models of wealth inequality: A survey. Tech. rep., National Bureau of Economic Research.

Fagereng, A., Guiso, L. and Pistaferri, L. (2017). Portfolio choices, firm shocks, and uninsurable wage risk. The Review of Economic Studies, 85 (1), 437-474.

Fox, J. T. and Smeets, V. (2011). Does input quality drive measured differences in firm productivity? International Economic Review, 52 (4), 961-989.

Friedrich, B., Laun, L., Meghir, C. and Pisteferri, L. (2014). Earnings Dynamics and Firm-Level Shocks. Working paper.

Gandhi, A., Navarro, S. and Rivers, D. (2018). On the identification of gross output production functions.

Gottschalk, P., Moffitt, R., Katz, L. F. and Dickens, W. T. (1994). The growth of earnings instability in the us labor market. Brookings Papers on Economic Activity, 1994 (2), $217-272$.

Guiso, L., Pistaferri, L. and Schivardi, F. (2005). Insurance within the firm. Journal of Political Economy, 113 (5), 1054-1087.

Guvenen, F. (2007). Learning your earning: Are labor income shocks really very persistent? American Economic Review, 97 (3), 687-712. 
-, Karahan, F., Ozkan, S. and Song, J. (2015). What do data on millions of US workers reveal about life-cycle earnings risk? Tech. rep., National Bureau of Economic Research.

- Ozkan, S. and Song, J. (2014). The nature of countercyclical income risk. Journal of Political Economy, 122 (3), 621-660.

Heckman, J. J. (1979). Sample selection bias as a specification error. Econometrica, 47 (1), $153-161$.

Jakobsen, K., Jakobsen, K., Kleven, H. and Zucman, G. (2017). Wealth taxation and wealth inequality: Evidence from denmark 1980-2014.

Juhn, C., McCue, K., Monti, H. and Pierce, B. (2018). Firm performance and the volatility of worker earnings. Journal of Labor Economics, 36 (S1), S99-S131.

Lamadon, T., Mogstad, M. and Setzler, B. (2017). Earnings Dynamics, Mobility Costs and Transmission of Firm and Market Level Shocks. Tech. rep.

Levinsohn, J. and Petrin, A. (2003). Estimating production functions using inputs to control for unobservables. The Review of Economic Studies, 70 (2), 317-341.

Low, H., Meghir, C. and Pistaferri, L. (2010). Wage risk and employment risk over the life cycle. American Economic Review, 100 (4), 1432-67.

Rute Cardoso, A. and Portela, M. (2009). Micro foundations for wage flexibility: wage insurance at the firm level. Scandinavian Journal of Economics, 111 (1), 29-50.

Sabelhaus, J. and Song, J. (2009). Earnings volatility across groups and time. National Tax Journal, pp. 347-364.

- and - (2010). The great moderation in micro labor earnings. Journal of Monetary Economics, 57 (4), 391-403.

Wooldridge, J. M. (2009). On estimating firm-level production functions using proxy variables to control for unobservables. Economics Letters, 104 (3), 112-114.

Ziliak, J. P., Hardy, B. and Bollinger, C. (2011). Earnings volatility in america: Evidence from matched cps. Labour Economics, 18 (6), 742-754. 


\section{Appendix}

\section{A Worker Entry and Exit}

Not all workers choose or are able to accept changes in wages at their current firm or a new firm in response to changes in firm productivity. Some workers respond - either willingly or not - by entering non-employment in the following period either by becoming unemployed or exiting labor force entirely. Clearly an analysis of wage changes does not really apply to this group of individuals. However, they are still exposed to the employment effects of firmlevel TFP shocks, and this passthrough may be just as significnat and heterogeneous as the passthrough to wages. So instead of estimating TFP changes effect on workers wage changes, we estimate if the probability of transitioning from employment to non-employment vs. to other firms becomes higher or lower when firms experience large TFP shocks. Furthermore, we investigate the effect of a firm's TFP changes on the probability of hiring workers out of non-employment relative to hiring from other firms. The regression model is as follows:

$$
S_{i j t}=\alpha+\beta \Delta T F P_{j t}+X_{i j t} \gamma+\varepsilon_{i j t}
$$

where $S_{i j t}$ denotes the indicator of individual $i$ 's status change between period t-1 and t. For example, $S_{i j t}$ might equal 1 if the worker switches from their current firm in period t into unemployment in $\mathrm{t}+1$ and 0 otherwise. Alternately, it might indicate that a workers switched from unemployment in $\mathrm{t}-1$ to their current firm in period t. $\triangle T F P_{j t}$ indicates firm j's TFP change between t-1 and t. $X_{i j t}$ includes the workers characteristics as well as the spousal characteristics we include in the selection model. $\beta$ is the parameter of interest, which measures the effect of firm level idiosyncratic TFP changes on worker probabilities of changing status.

The results of this analysis is shown in Table 13. The top panel of Table 13 shows the results for workers moving in and out of non-employment whereas the bottom panel shows the result for job switchers. The left two columns show the effect of TFP shocks on a worker's

probability of moving into non-employment or another job. The sample here includes workers who will stay at their firm. The right two columns show the results for workers who move to firm $j$ in period t. The sample here is workers who were not working at firm $j$ in t-1. Looking at the top panel, the results suggest that the bigger the size of the TFP shock (positive or negative), the more likely workers will switch out of their firm into non-employment. 
Positive TFP shocks have a stronger effect on switching out: when firms experience a $1 \%$ TFP increase, the probability that workers move out to non-employment increases by $3.4 \%$. A corresponding negative shocks also drives this up by $0.2 \%$. This suggests that firms adjust their labor composition in reaction to large changes in TFP in either direction. The right two columns tell a strikingly different story where large changes in TFP make it more likely that a newly employed worker is coming from unemployment. Positive shocks increase the probability by $2.6 \%$ while $1 \%$ negative shocks also increase the probability by $1.5 \%$. This is consistent with the churning story that when firms experiencing large TFP change, there will be more hiring and firing (churning). Looking at the bottom panel, we see that the TFP shocks have a very large effect on the probability of a worker leaving for another firm. As in the selection story, both large positive and negative shocks induce exit to other firms, which much larger magnitudes than for movements to non-employment. A $1 \%$ increase in tfp leads to a $19.3 \%$ increase in the probability that a worker switches to another firm. Finally, conditional on switching (as opposed to staying in the same firm between $\mathrm{t}-1$ and $\mathrm{t}$ ), workers entering a firm experiencing large positive shocks are less likely be coming from another firm relative to unemployment. However the are more likely to come from other firms if the TFP shock is negative. The asymmetry on the bottom panel is due to the differences in the sample in our analysis.

The results in this section further confirmed the importance of properly correcting for selection bias: when firms shocks are big (positive and negative), workers are more likely to switch out to another job and to unemployment. This biases our stayer and switcher analysis and therefore carefully correcting for this bias makes a stark difference in our results.

Table 13: Moving In and Out of Employment

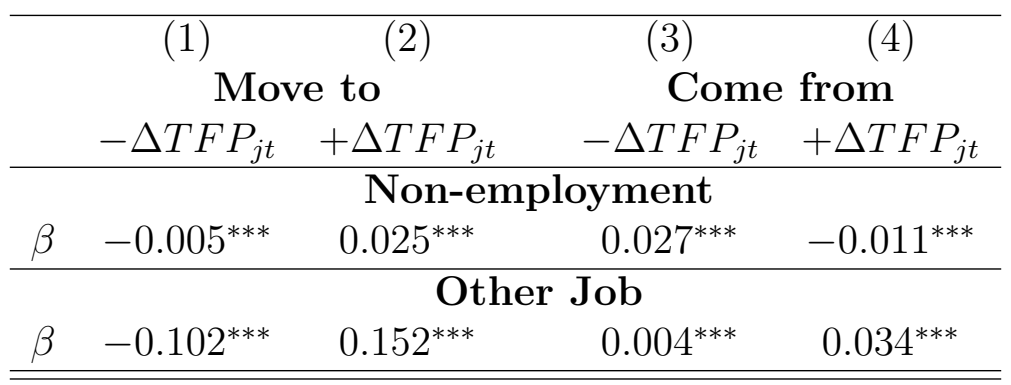

Note: Table 13 shows a set of linear probability regressions controlling for firm and worker characteristics. In columns $1-2$, the dependent variable is an indicator which is 1 if the individual moves from employment to non-employment (top panel) or another employer (bottom panel). In columns 3-4, the dependent variable is an indicator which is 1 if the individual has moved to their current job from non-employment (top panel) or another employer (bottom panel). The main explanatory variable is the change in within-firm (log) TFP spanning the individual's transition into or out of the firm. $* p<0.1, * * p<0.05, * * * p<0.01$. Robust standard errors are clustered at the firm level. 


\section{A.1 Permanent vs. Transitory Shocks}

One potential concern about the analysis presented so far is that we have not employed any distinction between permanent and transitory shocks to the firms. In particular, the regression approach we have considered has thus far been silent about whether the firm offers more insurance to persistent or permanent shocks relative to transitory shocks, which in theory could be easily insured-away by workers. In this section we first follow the standard approach adopted in the literature to separate the effect of persistent from transitory shocks to firms on workers' wages. We then discuss an approach to pursuing this analysis within our own framework.

In particular we follow Guiso et al. (2005) and Fagereng et al. (2017) to model the log of labor earnings as

$$
\log w_{i j t}=\mathbb{Z}_{i j t} \Gamma+\nu_{i t}+\theta^{P} Q_{j t}+\theta^{T} f_{j t}
$$

where $\mathbb{Z}_{i j t}$ is a set of characteristics for individual $i$ that works in firm $j$ in period $t$. The value of $\nu_{i t}$ is a pure transitory shock affecting worker's earnings, $Q_{j t}$ is the permanent component of the profitability shock affecting firm $j$, and $f_{j t}$ is the transitory component of the shocks to the firm. Similarly, we model the firm-level measure of interest $j$ as

$$
\log Y_{j t}=X_{j t} \varphi+Q_{j t}+f_{j t}
$$

where $X_{j t}$ is a vector of observable firm characteristics such as industry, firm age, and size.

Table 14: Permanent vs. Transitory Shocks

\begin{tabular}{ccccccc}
\hline & $(1)$ & \multicolumn{2}{c}{$(2)$} & $(3)$ & $(4)$ & \multicolumn{2}{c}{$(5)$} & $(6)$ \\
& & \multicolumn{2}{c}{ This Paper } & & \multicolumn{2}{c}{ Fagereng et al. (2018) } \\
& $\theta^{P}$ & $\theta^{T}$ & $\theta^{P}$ & $\theta^{T}$ & $\theta^{P}$ & $\theta^{T}$ \\
\hline \multirow{2}{*}{ Passthrough } & $0.074^{* * *}$ & $0.015^{* * *}$ & $0.028^{* * *}$ & $0.004^{* * *}$ & $0.071^{* * *}$ & $0.018^{* * *}$ \\
& & & & & & \\
\hline Firm Shock & VA & VA & TFP & TFP & VA & VA \\
\hline \hline
\end{tabular}

Note: Table 14 shows the results of estimating the model described by equations 15 and 16 . Columns $1-2$ show the results of estimating the model on the Danish data using the same definition of a firm shock as Guiso et al. (2005) and Fagereng et al. (2017). Columns 3-4 show the results of estimating the model using our definition of a firm shock (TFP). Columns 5-6 are the results obtained in Norwegian data by Fagereng et al. $(2017) . * p<0.1, * * p<0.05, * * * p<0.01$.

Guiso et al. (2005) have shown that the factor loadings $\theta^{P}$ and $\theta^{T}$ can be estimated using lags of the change in income growth and estimates of the shocks affecting the firm. Table 14 shows the results using this methodology. Columns (1) and (2) show the passthrough 
coefficient of permanent and transitory shocks when one considers value added as a measure of firm performance, similar to the existing literature. As in other papers (the results from Fagereng et al. (2017) are shown in columns 5 and 6), we find that the response of workers' wages to permanent shocks to firm's performance is significantly higher than the response to transitory shocks. Using TFP as a measure of firm performance - which is the measure used in this paper - provides lower estimates of passthrough overall. One reason we do not

pursue this methodology is because it's not clear how one would investigate passthrough to switchers, as the model is only defined for stayers. Their approach is also not able to separately identify permanent and transitory shocks - all that is identified is the convolution of the two (see footnote 23 in Guiso et al. (2005)). This prevents the direct analysis of the asymmetric responses of wages to positive and negative shocks to these components, which is one of the primary contributions of this paper. Similarly it's not clear how one would deal with selection in this setting, which is possibly why existing papers using this methodology have not attempted to tackle the selection bias problem.

\section{B Alternative TFP Estimation}

Our alternate TFP estimation strategy follows Wooldridge (2009) and Levinsohn and Petrin (2003). Specifically, we estimate the following production function (in logs):

$$
y_{j t}=\alpha k_{j t}+\beta \ell_{j t}+\gamma m_{j t}+a_{j t}
$$

$y_{j t}$ denotes firm $j$ 's (delflated) revenue at time $t . k_{j t}$ denotes the capital stock, $\ell_{j t}$ is the firm's labor inputs, and $m_{j t}$ denotes the firm's intermediate expenditure. We follow the literature in assuming that $(\log ) \mathrm{TFP}, a_{j t}$, can be decomposed into permanent $\left(\omega_{j t}\right)$ and transitory $\left(\varepsilon_{j t}\right)$ components, and that $\omega_{j t}$ is 1 st order Markov

$$
\omega_{j t}=g\left(\omega_{j t-1}\right)+\eta_{j t}
$$

where $\eta_{j t}$ denotes the random deviation from the permanent component. $g($.$) is an unknown$ function representing the conditional mean of the permanent component of productivity which we will approximate with a high order polynomial. We further assume that $\varepsilon_{j t}$ is iid and mean independent, such that we normalize $\mathbb{E}\left[\varepsilon_{j t}\right]=0$. We can thus express $(\log )$ TFP in the following form:

$$
a_{j t}=g\left(\omega_{j t-1}\right)+\eta_{j t}+\varepsilon_{j t}
$$


Following the Wooldridge (LP) proxy method, we get consistent estimates of $\alpha, \beta, \gamma, g$, and recover $\widehat{a}_{j t}$ which is our measure of TFP. In our robustness check regression analysis in section ??, we directly control for factors in $\omega_{j t-1}$, so the passthrough effect that we estimate is essentially the effect of $\eta_{j t}$ and $\varepsilon_{j t}$ combined. Note that the recent literature (ACF and GNR in particular) has cast some doubt on the degree to which these proxy methods can truly identify gross production functions. However, this method is ubiquitous in the empirical literature, and so we think it appropriate for our baseline robustness exercise.

\section{Model Extension}

In this section, we consider the full model with selection. We allow for full asymmetric passthrough between positive and negative shocks, and we allow heterogeneous passthrough between stayers and switchers. This work is still ongoing.

Consider that log-wage of invidiual $i$ that workes in firm $j$ in period $t$ is given by:

$$
\begin{aligned}
\log y_{i, j, t}= & d_{t}+X_{i, t}^{\prime} \gamma+\eta_{i, t}+\varepsilon_{i, t} \\
+ & +\psi_{0 i, j, s} z_{j, t-1}+\psi_{1 i, j, s} \Delta z_{j, t} \mathbf{1}_{\Delta z_{j, t}>0} \mathbf{1}_{S_{t}}+\psi_{2 i, j, s} \Delta z_{j, t} \mathbf{1}_{\Delta z_{j, t} \leq 0} \mathbf{1}_{S_{t}} \\
& +\psi_{3 i, j, s} \Delta z_{j, t} \mathbf{1}_{\Delta z_{j, t}>0} \mathbf{1}_{M_{t}}+\psi_{4 i, j, s} \Delta z_{j, t} \mathbf{1}_{\Delta z_{j, t} \leq 0} \mathbf{1}_{M_{t}}
\end{aligned}
$$

$d_{t}$ represents the average $\log$ price of human capital at time $t, X_{i t}$ is a set of workers' characteristics including age. The indicator $\mathbf{1}_{M_{t}}$ is equal to one when a worker is new to firm $j$. This wage process has a richer structure compare to the wage process in equation 12 in two ways: 1. it includes individual characteristics and time effects; 2 . It allows the switchers and stayers to have different wage passthrough, in levels and changes. This implies:

$$
\begin{aligned}
\Delta \log y_{i j t}= & \Delta d_{t}+\Delta X_{i t}^{\prime} \gamma+\Delta \eta_{i, t}+\Delta \varepsilon_{i t} \\
& +\left(\psi_{1} \mathbf{1}_{\Delta z_{j, t}>0, S}+\psi_{2} \mathbf{1}_{\Delta z_{j, t} \leq 0, S}+\psi_{3} \mathbf{1}_{\Delta z_{j, t}>0, M}+\psi_{4} \mathbf{1}_{\Delta z_{j, t} \leq 0, M}\right) \Delta z_{j, t} \\
& +\left(\psi_{0}-\psi_{1} \mathbf{1}_{\Delta z_{j, t-1}>0, S}-\psi_{2} \mathbf{1}_{\Delta z_{j, t-1} \leq 0, S}\right) \Delta z_{j, t-1} \\
& +\left(\psi_{0}-\psi_{1} \mathbf{1}_{\Delta z_{j, t-1}>0, M}-\psi_{2} \mathbf{1}_{\Delta z_{j, t-1} \leq 0, M}\right) \Delta z_{j, t-1}
\end{aligned}
$$

We could estimate all the parameters either using SMM (2 additional parameters, so add 2 more moments for movers), or use LMP's method, and directly back out all the parameters by algebra. 


\section{C.1 Consumption Saving Model}

Here we apply the wage process from the previous section into a simple consumption saving model. We allow workers to stay or switch jobs, because selection is in the center of our analysis. However, we do not consider workers being unemployed for now, because it is not of our key interests: the passthrough from firms to workers. Adding unemployment will add one additional dimension to our state space so we are leaving it out for now. We'll add it in when we consider workers unemployment risk, for example, a worker who is working at a low TFP firm or decreasing TFP firm will have a higher probability of separation.

Individuals chooses their consumption level to maximize their life time utility

$$
\begin{aligned}
& V\left(a_{i, t}, \eta_{i, t}, z_{j, t}, z_{j, t-1}, M_{i, t}, M_{i, t-1}, a g e\right)=\max _{c_{i, t}, a_{i, t+1}}\left\{\frac{c_{i, t}^{1-\varepsilon}}{1-\varepsilon}+\right. \\
& \beta\left(1-\lambda^{e}\right) \mathbb{E}_{\zeta_{j, t+1}, \xi_{j, t+1}}\left[V\left(a_{i, t+1}, \eta_{i, t+1}, z_{j, t+1}, z_{j, t}, 0, M_{i, t}, a g e^{\prime}\right)\right] \\
& \left.+\beta \lambda^{e} \mathbb{E}_{\zeta_{j, t+1}, \xi_{j, t+1}}\left[\max \left\{V\left(a_{i, t+1}, \eta_{i, t+1}, z_{j, t+1}, z_{j, t}, 0, M_{i, t}, a g e^{\prime}\right), V\left(a_{i, t+1}, \eta_{i, t+1}, z_{j^{\prime}, t+1}, z_{j, t}, 1, M_{i, t}, a g e^{\prime}\right)\right\}\right]\right\} \\
& \text { s.t. } \quad c_{i, t}+a_{i, t+1} \leq\left(1+r_{t}\right) a_{i, t}+y_{i, j, t}
\end{aligned}
$$

$$
\begin{aligned}
& \log y_{i, j, t}=d_{t}+X_{i, t}^{\prime} \gamma+\eta_{i, t}+\varepsilon_{i, t} \\
& +\psi_{0 i, j, s} z_{j, t-1}+\psi_{1 i, j, s} \Delta z_{j, t} \mathbf{1}_{\Delta z_{j, t}>0} \mathbf{1}_{S_{t}}+\psi_{2 i, j, s} \Delta z_{j, t} \mathbf{1}_{\Delta z_{j, t} \leq 0} \mathbf{1}_{S_{t}} \\
& +\psi_{3 i, j, s} \Delta z_{j, t} \mathbf{1}_{\Delta z_{j, t}>0} \mathbf{1}_{M_{t}}+\psi_{4 i, j, s} \Delta z_{j, t} \mathbf{1}_{\Delta z_{j, t} \leq 0} \mathbf{1}_{M_{t}} \\
& z_{j^{\prime}, t+1} \sim \mathbb{N}\left(\frac{c_{j}}{1-\rho_{j}}, \frac{\sigma_{\xi}^{2}}{1-\rho_{j}^{2}}\right)
\end{aligned}
$$

